\title{
Acetaldehyde exchange above a managed temperate mountain grassland
}

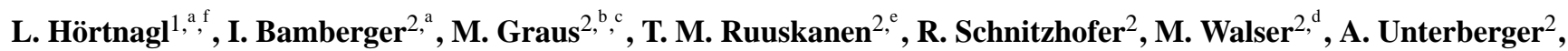 \\ A. Hansel $^{2}$, and G. Wohlfahrt ${ }^{1}$ \\ ${ }^{1}$ Institute of Ecology, University of Innsbruck, Austria \\ ${ }^{2}$ Institute of Ion Physics and Applied Physics, University of Innsbruck, Austria \\ a now at: Institute of Agricultural Sciences, ETH-Zürich, Switzerland \\ b now at: Cooperative Institute for Research in Environmental Sciences, University of Colorado, Boulder, CO 80309, USA \\ ' now at: Chemical Sciences Division, Earth System Research Laboratory, National Oceanic and Atmospheric Administration, \\ Boulder, CO 80305, USA \\ now at: Engineering Exhaust Gas Sensors, Robert Bosch GmbH, Stuttgart, Germany \\ e currently at: Division of Atmospheric Sciences, University of Helsinki, Finland \\ ${ }^{\mathrm{f}}$ Invited contribution by L. Hörtnagl, recipient of the EGU Outstanding Student Poster (OSP) Award 2011.
}

Correspondence to: L. Hörtnagl (lukas.hoertnagl@usys.ethz.ch)

Received: 6 August 2013 - Published in Atmos. Chem. Phys. Discuss.: 10 October 2013

Revised: 7 April 2014 - Accepted: 14 April 2014 - Published: 3 June 2014

\begin{abstract}
An overview of acetaldehyde exchange above a managed temperate mountain grassland in Austria over four growing seasons is presented. The meadow acted as a net source of acetaldehyde in all 4 years, emitting between 7 and $28 \mathrm{mg} \mathrm{C} \mathrm{m}^{-2}$ over the whole growing period. The cutting of the meadow resulted in huge acetaldehyde emission bursts of up to $16.5 \mathrm{nmol} \mathrm{m}^{-2} \mathrm{~s}^{-1}$ on the day of harvesting or 1 day later. During undisturbed conditions both periods with net uptake and net emissions of acetaldehyde were observed. The bidirectional nature of acetaldehyde fluxes was also reflected by clear diurnal cycles during certain time periods, indicating strong deposition processes before the first cut and emission towards the end of the growing season.

The analysis of acetaldehyde compensation points revealed a complex relationship between ambient acetaldehyde mixing ratios and respective fluxes, significantly influenced by multiple environmental parameters and variable throughout the year. As a major finding of this study, we identified both a positive and negative correlation between concentration and flux on a daily scale, where soil temperature and soil water content were the most significant factors in determining the direction of the slope. In turn, this bidirectional relationship on a daily scale resulted in compensation points between 0.40 and 0.54 ppbv, which could be well explained by
\end{abstract}

collected ancillary data. We conclude that in order to model acetaldehyde fluxes at the site in Neustift on a daily scale over longer time periods, it is crucial to know the type of relationship, i.e., the direction of the slope, between mixing ratios and fluxes on a given day.

\section{Introduction}

In recent years, technological progress and new measurement techniques facilitated the in situ measurement of volatile organic compounds (VOC) over longer time periods. The quantification of VOC exchange over different ecosystems and at different temporal and spatial scales contributed towards an improved understanding of the complex interactions between VOCs and the atmosphere (Goldstein and Galbally, 2007). While the processes underlying the exchange of some VOCs have been studied extensively (e.g., isoprene), knowledge for many other VOCs is still limited.

In the past, most studies have focused on the highly reactive isoprenoids over forest due to their significant role in atmospheric chemistry (Sharkey et al., 2008). In contrast, only few field campaigns targeted the group of short-chained oxygenated volatile organic compounds (OVOCs) which 
are abundant throughout the troposphere (e.g., Singh et al., 2004), e.g., formaldehyde, acetaldehyde, acetone, methanol and ethanol (Seco et al., 2007). Especially over grassland, little is known about the interannual and seasonal variability of biogenic OVOC fluxes.

Acetaldehyde $\left(\mathrm{CH}_{3} \mathrm{CHO}\right)$ is a reactive compound with an atmospheric lifetime of a few hours during summer (Atkinson, 2000; Atkinson et al., 2006; Possanzini et al., 2002). Its photo-oxidation contributes to the radical budget in the troposphere (Seinfeld and Pandis, 2006) and pollutants like PAN (Roberts, 1990) and $\mathrm{O}_{3}$ are formed in the process. Increased $\mathrm{O}_{3}$ levels in the troposphere affect plant growth and human health (Kotzias et al., 1997).

Recent studies have reported bidirectional exchange of acetaldehyde with the atmosphere (Fall, 2003; Graus et al., 2013; Karl et al., 2010), but our current knowledge about acetaldehyde production and consumption in plants is still limited (Jardine et al., 2008).

Secondary photochemical production was described as the major source of atmospheric acetaldehyde on a global scale (Atkinson et al., 2006) and as much larger than biogenic emissions, which in turn are the dominant direct terrestrial source of atmospheric acetaldehyde (Millet et al., 2010). Acetaldehyde can also be emitted from decaying plant matter (Greenberg et al., 2012) and as a consequence of photodegradation of colored dissolved organic matter (Kieber et al., 1990; Zhou and Mopper, 1997). Other terrestrial sources include animals (Rumsey et al., 2012), biomass burning and anthropogenic emissions (Langford et al., 2009; Millet et al., 2010).

Previous studies described a clear dependence of acetaldehyde emission rates on light and temperature (Brilli et al., 2011; Cojocariu et al., 2004; Filella et al., 2007; Hayward et al., 2004; Kondo et al., 1998; Ku et al., 2000; Schade and Goldstein, 2002). Karl et al. (2002a) attributed emission bursts after light-dark transitions to a "pyruvate overflow" mechanism in which acetaldehyde is formed directly in leaves through the decarboxylation of pyruvate as part of the pyruvate dehydrogenase bypass pathway. Findings by Jardine et al. (2012) were consistent with this explanation. In a fumigation experiment with trees, Kondo et al. (1998) found a linear relationship between acetaldehyde absorption and transpiration under varying light conditions and a clear increase of acetaldehyde uptake with rising total ambient $\mathrm{C}_{2}-$ $\mathrm{C}_{5}$ aldehydes volume mixing ratios (VMR) up to $3000 \mathrm{ppbv}$. In order to explain this continuous sink, the study suggests a biological removal process mediated by stomata and that trees could act as an important sink for $\mathrm{C}_{2}-\mathrm{C}_{5}$ aldehydes. Jardine et al. (2008) pointed out that a chemical reaction of acetaldehyde with the leaf surface is unlikely, since it mainly consists of inert alkanes (waxes). Acetaldehyde deposition to the leaf cuticle has been described for leaves of Amazonian floodplain tree species (Rottenberger et al., 2008). Kreuzwieser et al. (2001) described acetaldehyde as relatively insensitive to stomatal conductance for leaves of trees, but described an indirect effect by controlling transpiration rates and therefore the amount of ethanol transported to the leaves from the roots. A lack of stomatal influence and physiological parameters on observed acetaldehyde fluxes was also reported by other investigations (Kesselmeier and Staudt, 1999; Kesselmeier, 2001; Martin et al., 1999). For forest canopies, Jardine et al. (2008) reported that stomatal conductance controls acetaldehyde exchange rates but does not affect internal acetaldehyde concentrations due to continuous production and consumption processes. In addition, acetaldehyde has been shown to be released from young seedlings during the first days of germination (Stotzky et al., 1976).

Ethanol, an important precursor for acetaldehyde, is produced in plant roots during anoxic conditions, e.g., caused by soil flooding, through alcoholic fermentation and subsequently transported to the leaves via the transpiration stream. In the leaves and mediated by alcohol dehydrogenase (ADH), ethanol is oxidized, generating acetaldehyde as an intermediate (Kreuzwieser et al., 1999, 2004). Because acetaldehyde itself is subsequently oxidized by the action of aldehyde dehydrogenase, Kreuzwieser et al. (2001) considered the emission of acetaldehyde as a leak between its production and metabolism and affiliated diurnal changes of acetaldehyde emission with the amount of ethanol that was produced and transported to the leaves since the enzymatic activity of ADH remained constant. This pathway may be a significant source of acetaldehyde on a global scale, for example during the wet season in the Amazon rain forest when the roots are flooded (Rottenberger et al., 2008). However, Jardine et al. (2008) described that this fermentation process may also be active in leaves under aerobic conditions.

The dominant sink of atmospheric acetaldehyde is assumed to be its reaction with $\mathrm{OH}$ (Atkinson et al., 2006), and to a lesser degree photolysis (Sander et al., 2006). Studies have shown that plants can also act as a sink for acetaldehyde (e.g., Karl et al., 2005; Rottenberger et al., 2004), for example when it is enzymatically oxidized to acetate and subsequently metabolically consumed (Fall, 2003). Recently, both wet and dry deposition have been described (Custer and Schade, 2007; Karl et al., 2004; Warneke et al., 2002). Slow deposition rates to the soil surface were reported by Schade et al. (2011).

An acetaldehyde compensation point $\left(C^{*}\right)$ for leaves has been described previously (Kesselmeier, 2001) and is defined as the ambient concentration at which the net exchange between the ecosystem and the atmosphere is zero. With ambient concentrations below $C^{*}$, acetaldehyde is emitted from the leaves, while the compound is taken up when ambient concentrations are above $C^{*}$. When the production within the leaves dominates, $C^{*}$ is high, whereas it is low if consumption processes play a more important role (Jardine et al., 2008). $C^{*}$ measurements of acetaldehyde are still rare and have only been conducted in a small number of studies, e.g., for Norway spruce (Cojocariu et al., 2004) and Amazonian 
tree species (Rottenberger et al., 2004). However, it seems that physiological factors can influence observed compensation points, like species composition and leaf age (Rottenberger et al., 2005). A previous study showed that environmental variables like rising temperatures may increase the $C^{*}$, implying that production is more sensitive to temperature than the consumption in plants (Karl et al., 2005).

Recent studies described acetaldehyde exchange patterns varying with height in the plant canopy. Flux measurements within the canopy showed net emission in the upper canopy and net uptake deeper within the canopy over a Norway spruce forest (Müller et al., 2006) and in the Amazon (Rottenberger et al., 2004). Cojocariu et al. (2004) reported branch enclosure emission rates by spruce trees increasing with canopy height.

Karl et al. (2005) reported emission at the top of a loblolly pine plantation and uptake in the canopy, where the strongest uptake occurred in regions with the highest leaf area index (LAI). The same study observed highest acetaldehyde concentrations at the top of the canopy, where also highest emission fluxes were measured. In turn, lowest concentrations were reported from the lower part of the canopy, where the highest uptake rates of acetaldehyde were quantified. Assuming a fixed $C^{*}$, this exchange pattern cannot be explained (Jardine et al., 2008). The distinct diurnal cycle of acetaldehyde exchange reported by several studies supports the idea that diurnal variation in temperature and radiation influences $C^{*}$ and therefore the flux rate (Cojocariu et al., 2005; Jardine et al., 2008).

The present study focuses on acetaldehyde, one of the three major biogenic OVOCs besides methanol and acetone found during undisturbed conditions above a grassland near Neustift, Austria (Bamberger et al., 2010). To this end we investigated 4 years of diurnal, seasonal and interannual acetaldehyde exchange rates and elucidated observed flux patterns in relation to biotic and abiotic drivers under in situ conditions at ecosystem scale. The objective of this paper is to compare our findings to previous results at leaf or ecosystem level, to elaborate possible causes for observed differences to other studies and to refine our understanding of long term acetaldehyde fluxes. Based on previous findings we hypothesized that during undisturbed conditions (1) emission rates of acetaldehyde are influenced by light and temperature. As shown in an earlier study for methanol (Hörtnagl et al., 2011), we further hypothesized that (2) the cutting of the meadow results in high acetaldehyde emissions that constitute a major influence on resulting acetaldehyde budgets. In addition, as several studies have described a compensation point for acetaldehyde (Cojocariu et al., 2004; Kesselmeier, 2001; Rottenberger et al., 2004), we assumed that (3) a compensation point can be found over our grassland at ecosystem scale and that (4) $C^{*}$ varies over the course of a year due to environmental variables and ecosystem structure and function.
The study site Neustift, a managed temperate mountain grassland in Austria that is cut three times per year for hay production, was selected because it has been the focus of numerous studies over the last 10 years and is therefore well described in terms of management effects, net ecosystem $\mathrm{CO}_{2}$ and energy exchange (Hammerle et al., 2008; Wohlfahrt et al., 2008) and VOC exchange (Bamberger et al., 2010, 2011; Brilli et al., 2012; Hörtnagl et al., 2011; Müller et al., 2010; Ruuskanen et al., 2011).

\section{Methods}

\subsection{Site description}

The study site is an intensively managed meadow situated at an elevation of $970 \mathrm{~m}$ a.s.l. near the village of Neustift $\left(47^{\circ} 07^{\prime} \mathrm{N}, 11^{\circ} 19^{\prime} \mathrm{E}\right)$ in the Stubai Valley (Austria) in the middle of the flat valley bottom. The fetch is homogeneous up to $300 \mathrm{~m}$ to the north-north-east and $900 \mathrm{~m}$ to the southsouth-west of the instrument tower, which are also the dominant daytime and nighttime wind directions, respectively, and parallel to the Valley's orientation. Typically, the atmosphere shows stable stratification during the night, resulting in a larger footprint than during daytime, where wind velocities are higher and conditions unstable (Bamberger et al., 2010). The average annual temperature at the study site is $6.5^{\circ} \mathrm{C}$, the average annual precipitation amounts to $852 \mathrm{~mm}$, a humid continental climate with alpine influences. The vegetation of the meadow consists mainly of a few dominant graminoids (Dactylis glomerata, Festuca pratensis, Phleum pratensis, Trisetum flavescens) and forbs (Ranunculus acris, Taraxacum officinale, Trifolium repens, Trifolium pratense, Carum carvi). The slopes of the surrounding mountains are dominated by coniferous forest.

Acetaldehyde measurements were conducted during 4 years between 22 May-20 November 2008 (182 days), 19 March-11 December 2009 (267 days), 18 March-12 December 2011 (269 days) and 27 March-25 November 2012 (243 days). In each year, the meadow was cut three times, with the first cut taking place between 4-10 June, the second cut between 31 July-10 August and the third cut between 21-28 September. In addition, the meadow was fertilized by manure spreading once per year, between 18-26 October. In 2008 and 2012 no data were recorded for both the day of the third cut and for the day of fertilization due to instrument failure. The meadow was snow-covered for the first 10 and the last 11 days of measurements in 2009 and for the last 5 days of the campaign in 2011.

\subsection{Eddy covariance measurements}

The net ecosystem acetaldehyde exchange was calculated by combining the three-dimensional wind speed and the speed of sound measured with a sonic anemometer (R3IA, Gill Instruments, Lymington, UK) at a height of $2.5 \mathrm{~m}$ above ground 
with acetaldehyde VMRs that were simultaneously detected by a proton-transfer-reaction mass-spectrometer (PTR-MS) at $m / z 45$ using the virtual disjunct eddy covariance (vDEC) method proposed by Karl et al. (2002), which is based on the eddy covariance method (Baldocchi et al., 1988; McMillen, 1988). Air was sampled through an inlet located $0.1 \mathrm{~m}$ below the anemometer, drawn through a particulate filter $(1-2 \mu \mathrm{m}$, PTFE) and through a $16 \mathrm{~m}(2008) / 12 \mathrm{~m}(2009-2012)$ PFA Teflon tube with $0.004 \mathrm{~m}$ inner diameter and was finally analyzed for acetaldehyde and other VOCs by the PTR-MS. The inlet line was heated to $40^{\circ} \mathrm{C}(2008) / 35^{\circ} \mathrm{C}(2009-2012)$ to minimize adsorption of VOCs to the inlet line, the flow rate was held constant at 8/9 SLPM (standard liter per minute; air volume normalized to standard temperature and pressure conditions: $273 \mathrm{~K}, 1013 \mathrm{hPa}$ ) in 2008 and 2009-2012, respectively. Sonic anemometer data were stored to a hard drive of a personal computer using the Eddymeas software (O. Kolle, Max Planck Institute for Biogeochemistry, Jena, Germany).

\subsection{PTR-MS setup}

Acetaldehyde VMRs were quantified by a high-sensitivity proton-transfer-reaction mass-spectrometer (PTR-MS, working principle described by Hansel et al. (1995) and Lindinger et al. (1998)) that was deployed in a temperature controlled container next to the field site. Ambient air was analyzed for a number of compounds besides acetaldehyde. In 2008, 13 different $\mathrm{m} / \mathrm{z}$ values were recorded repeatedly, resulting in a cycle time of $2.82 \mathrm{~s}$ until $10 \mathrm{July}$, after which it was changed to $3.00 \mathrm{~s}$ ( 15 different $\mathrm{m} / z$ values) until 6 November 2008 and after that to $1.80 \mathrm{~s}(8 \mathrm{~m} / z$ values $)$ until 20 November. In 2009 the cycle time was $2.25 \mathrm{~s}$ until 6 April $(12 \mathrm{~m} / z$ values) and then $2.35 \mathrm{~s}$ until 11 December $(13 \mathrm{~m} / z$ values $)$. In both 2011 and 2012, the measurement cycle lasted $1.61 \mathrm{~s}$, targeting $9 \mathrm{~m} / z$ values. The mass to charge ratios measured for each year were $m / z 33$ (methanol), $m / z 45$ (acetaldehyde), $\mathrm{m} / \mathrm{z} 59$ (e.g., acetone, propanal), $\mathrm{m} / \mathrm{z} 137$ (sum of monoterpenes) and some additional $\mathrm{m} / \mathrm{z}$ ratios to quantify the primary ions and the main fragment of monoterpenes. The dwell time for acetaldehyde $(\mathrm{m} / \mathrm{z} 45)$ was $0.2 \mathrm{~s}$ in all years. During the last 5 minutes of every half-hour period, the instrumental background was recorded by flushing $500 \mathrm{~mL}$ of ambient air through a home-built catalytic converter (heated to $350^{\circ} \mathrm{C}$ ). The PTR-MS was calibrated once a week in 2008 (as well as directly before and after each maintenance, e.g., exchange of the ion source) and every $50 \mathrm{~h}$ in 2009/2011/2012 by diluting a multi-component gas standard containing VOCs in ppm volume mixing ratios in $\mathrm{N}_{2}$ (Apel Riemer Inc., USA) in VOC-free ambient air. Typical calibration factors for acetaldehyde were 15/20/13/13 ncps (normalized counts per second, normalized to 1 million primary ions and $2.2 \mathrm{mbar}$ drift tube pressure; corresponding to approx. 80-120 counts per second) per ppbv in 2008/2009/2011/2012, respectively. The limit of detection (at $1 \mathrm{~s}$ dwell time) was calculated dur- ing each calibration and typically around $0.1 \mathrm{ppbv}$, except for 2008 when it was around a factor of 5 higher. The PTRMS was operated at a drift tube pressure of $2.15 / 2.3 \mathrm{mbar}$ and a drift voltage of 550/600 V during 2008/2009-2012 respectively. Data were stored in $30 \mathrm{~min}$ files and processed to yield VOC volume mixing ratios in ppbv using a homemade application written in the MATLAB programming language (version 7.4.0, release R2007a, The MathWorks, Inc., USA). More information regarding setup, calibration and operation of the PTR-MS instrument at the site can be found in earlier studies (Bamberger et al., 2010, 2011; Hörtnagl et al., 2011). For a period of 35 days from June to August 2009, a proton-transfer-reaction time-of-flight mass-spectrometer (PTR-TOF) and a PTR-MS were simultaneously recording VOC fluxes at the field site in Neustift. During this period no eddy covariance flux was found at the exact mass of $\mathrm{CO}_{2} \mathrm{H}^{+}(\mathrm{m} / 244.998)$, a potential interfering compound of protonated acetaldehyde $\left(\mathrm{CH}_{3} \mathrm{HCOH}^{+} \mathrm{m} / z\right.$ 45.0340) in PTRMS. As shown in the Supplement, eddy covariance flux values obtained with PTR-TOF at $m / z 45.0340$ were in excellent agreement with flux values from the PTR-MS at the nominal mass $m / z 45$ (Supplement Figs. S1-S3). We can therefore rule out erroneous contributions of $\mathrm{CO}_{2} \mathrm{H}^{+}$to acetaldehyde fluxes measured with PTR-MS at $m / z 45$.

\subsection{Flux calculations}

Half-hourly fluxes were calculated using ambient air measurements of the first $25 \mathrm{~min}$ of each $30 \mathrm{~min}$ period due to the zero calibration during the last 5 minutes. Because of the disjunct nature of the VMRs, the vDEC method (Karl et al., 2002) was applied to calculate acetaldehyde fluxes as the maximum covariance between the turbulent departures of the $20 \mathrm{~Hz}$ vertical wind speed and the lower resolved acetaldehyde VMRs. First, a homemade program was used for the time lag search between the two time series and subsequently the post-processing software EdiRe (University of Edinburgh) for final flux calculations by using a subsample of the horizontal wind data as given by the sampling rate of the PTR-MS. Means and turbulent departures were calculated by Reynolds (block) averaging. Hörtnagl et al. (2010) showed that the vDEC method yields unbiased flux estimates but is characterized by a larger random uncertainty compared to the true eddy covariance (EC).

Among all targeted VOCs the determination of the tubing induced delay time by optimizing the correlation coefficient of the VOC signal with the vertical wind velocity (McMillen, 1988) worked best for methanol, of which the frequency distribution of found lag times showed a peak around $1.5 \mathrm{~s}$ in all 4 years. Lag times for acetaldehyde were searched in a window of $\pm 3 \mathrm{~s}$ around this peak. If the time delay was outside of the pre-defined window, the acetaldehyde lag time was set to the peak of the methanol distribution (i.e., $1.5 \mathrm{~s}$ ).

Raw acetaldehyde fluxes were then corrected for high-pass (block averaging) and low-pass (lateral sensor separation, 
dynamic frequency response, scalar and vector path averaging, frequency response mismatch and the attenuation of concentration fluctuations down the sampling tube) filtering according to Moore (1986), Massman (2000) and Aubinet et al. (2000). Frequency-response corrections were based on a site-specific model cospectrum described by Wohlfahrt et al. (2005). Instrumentation, data treatment and quality control of $\mathrm{CO}_{2}$, sensible and latent heat fluxes have been described by Wohlfahrt et al. (2008) and Hammerle et al. (2008). The flux detection limit was calculated according to Karl et al. (2002) and found around $0.1 \mathrm{nmol} \mathrm{m}^{-2} \mathrm{~s}^{-1}$.

\subsection{Quality control}

Half-hourly acetaldehyde fluxes were excluded from further analysis if (i) the third rotation angle exceeded $10^{\circ}$ (McMillen, 1988), (ii) the stationarity test for acetaldehyde fluxes exceeded $60 \%$ (Foken and Wichura, 1996), (iii) the deviation of the integral similarity characteristics was larger than $60 \%$ (Foken and Wichura, 1996), (iv) the maximum of the footprint function (Hsieh et al., 2000) was outside the boundaries of the meadow, (v) the measured background signal of acetaldehyde was higher than its ambient concentration (averaged over half an hour) and (vi) the background drift was greater than the sum of the standard deviations of the two adjacent background measurements before and after the flux averaging period. Acetaldehyde VMR data points were flagged as an outlier if the difference between a specific data point and the averaged signal of the respective half-hour was higher than 20 times the theoretical standard deviation (noise). On days influenced by management no outliers were removed, as large fluctuations in acetaldehyde concentrations were found to be physically realistic. Half-hour periods with more than five outliers were rejected and not used in further analyses. In total over all 4 years, 38558 half-hourly fluxes of acetaldehyde were recorded, of which 27648 (72\%) passed all quality tests and were used in the present study.

\subsection{Ancillary data}

Meteorological measurements included total (PAR) and the fractions of diffuse $\left(\mathrm{PAR}_{\mathrm{di}} / \mathrm{PAR}\right)$ and reflected $\left(\mathrm{PAR}_{\text {refl }} / \mathrm{PAR}\right)$ photosynthetically active radiation $(\mathrm{BF} 3 \mathrm{H}$, Delta-T, Cambridge, UK), net radiation ( $R_{\text {net }}$; measured by CNR1, Kipp \& Zonen, Delft, Netherlands), air temperature $\left(T_{\text {air }}\right)$ and humidity at $2 \mathrm{~m}$ height measured by the means of a ventilated temperature/humidity sensor (RFT-2, UMS, Munich, Germany), soil heat flux (SHF) quantified by means of heat flux plates ( 3 replicates at $0.05 \mathrm{~m}$ depth, corrected for the change in heat storage above that depth; HFP01, Hukseflux, Delft, Netherlands), soil temperature $\left(T_{\text {soil }}\right)$ at $0.05 \mathrm{~m}$ depth (TCAV thermocouple, Campbell Scientific, Logan, UT, USA), volumetric soil water content (SWC) (ML2x, Delta-T Devices, Cambridge, UK) and precipitation (52202, R. M. Young, Traverse City, MI, USA). All data were collected continuously by a data logger (CR10X, Campbell Scientific, Logan, UT, USA). The green plant area index (GAI) was assessed (i) in a destructive fashion by harvesting the plant matter of square plots $\left(0.09 \mathrm{~m}^{2}, 3-5\right.$ replicates $)$ and subsequent plant area determination ( $\mathrm{Li}-3100$, Li Cor, Lincoln, NE, USA) and (ii) from measurements of canopy height which was related to destructively measured GAI (Wohlfahrt et al., 2008). Continuous time series of the GAI were derived by fitting appropriate empirical functions to measured data separately for each growing phase before and after cutting events. A more detailed list of all auxiliary parameters measured at this site is given by Wohlfahrt et al. (2008) and Hammerle et al. (2008).

\subsection{Statistical analyses}

Statistical analyses were done using Statistica 9 (StatSoft, Inc.), SigmaPlot 11 (Systat Software, Inc.) and Excel 2010 (Microsoft, Inc.). The partial correlation in multiple linear regression analyses gives the correlation between two variables after controlling for the effect of all other variables in the equation. The squared semi-partial correlation was used to express the unique variance accounted for by a specific predictor, relative to the total variance of a dependent variable. Tolerance is a measure of redundancy and defined as 1 minus the squared multiple correlation of a variable with all other independent variables in the regression equation. The higher the tolerance value of a predictor, the less redundant is its contribution to the regression. To determine significant differences between group means in an analysis of variance (ANOVA) setting, the Unequal N HSD post hoc test, a modification of the Tukey's HSD test, was used. For statistical analyses, only days or half-hours where all parameters were available were included.

\section{Results}

\subsection{Overview}

Figure 1 shows 844 daily average values of acetaldehyde fluxes over 4 measurement years, with 140 (2008), 249 (2009), 248 (2011) and 207 values (2012) for each single year. Both emission and deposition fluxes could be observed in all 4 years (Fig. 1). Between 2008 and 2012, the influence of management events, characterized by elevated emission fluxes, could be observed on a total of 37 days, all of which resulted in a daily net emission of acetaldehyde. During undisturbed conditions emission and deposition were recorded on $333(41 \%)$ and 474 days (59\%), respectively, and 80 days $(10 \%)$ showed strong daily average deposition fluxes below $-0.1 \mathrm{nmol} \mathrm{m}^{-2} \mathrm{~s}^{-1}$, while 79 days resulted in net emission fluxes that exceeded $0.1 \mathrm{nmol} \mathrm{m}^{-2} \mathrm{~s}^{-1}$ (Fig. 1). The average flux over all $4 \mathrm{yr}$ during undisturbed conditions was exactly zero, and only slightly higher with management events included $\left(0.04 \mathrm{nmol} \mathrm{m}^{-2} \mathrm{~s}^{-1}\right)$. 


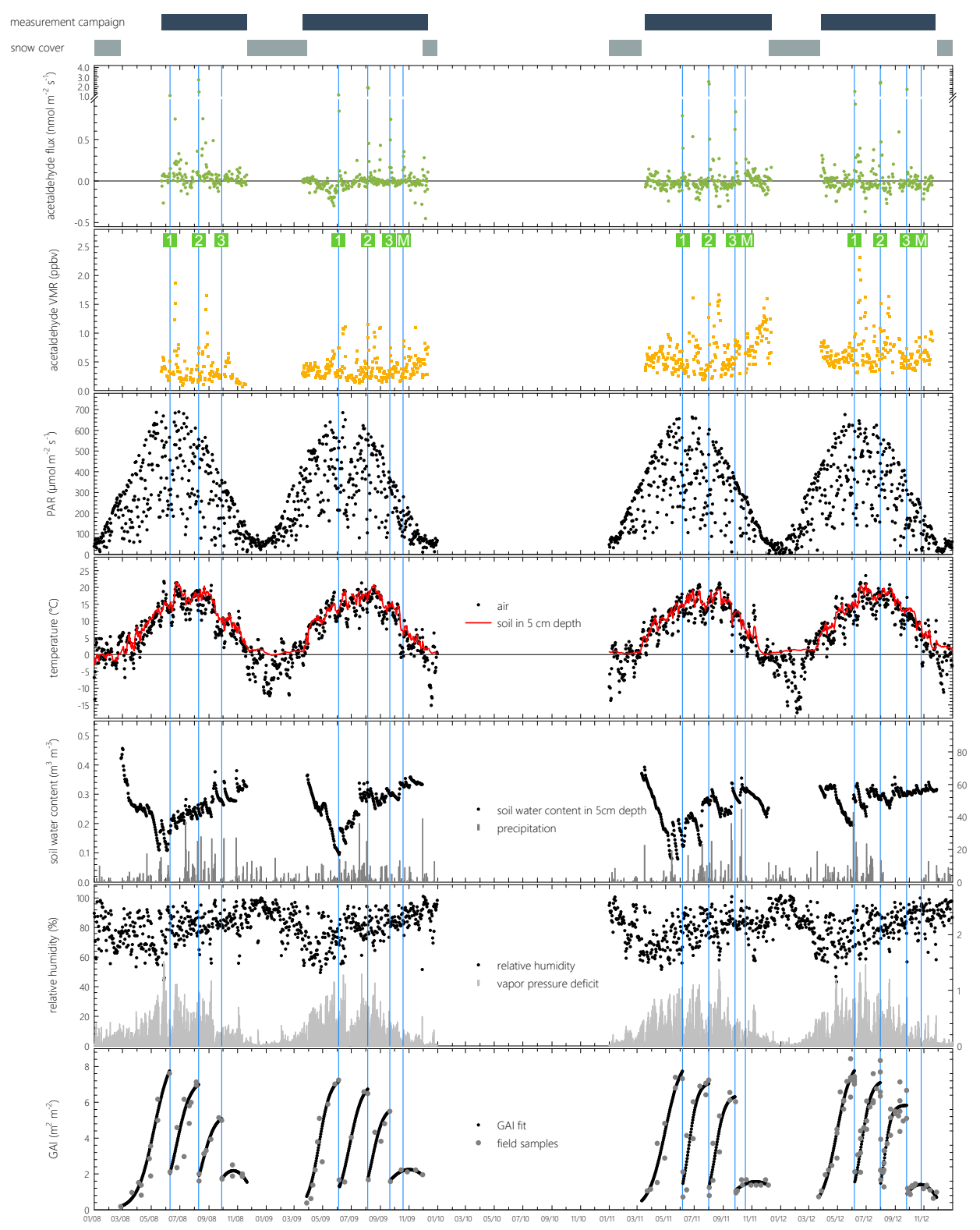

date (month/year)

Figure 1. Daily averages of acetaldehyde flux and volume mixing ratio (VMR), photosynthetically active radiation (PAR), air temperature, soil temperature in $5 \mathrm{~cm}$ depth, soil water content in $5 \mathrm{~cm}$ depth, relative humidity, vapor pressure deficit, green plant area index (GAI) and daily sums of precipitation over 4 years of VOC measurements from 2008-2009 and 2011-2012. Vertical lines show management dates, numbers 1, 2 and 3 in green squares mark the first, second and third cutting of the meadow, respectively, while $M$ denotes manure spreading.

Highest daily average acetaldehyde fluxes in each year were observed on the day of the second cutting of the meadow, reaching emission values between $1.89-2.69 \mathrm{nmol} \mathrm{m}^{-2} \mathrm{~s}^{-1}$. During undisturbed conditions, maximum emissions of $0.75 \mathrm{nmol} \mathrm{m}^{-2} \mathrm{~s}^{-1}$ were observed in June and August 2008. Highest deposition fluxes of more than $-0.3 \mathrm{nmol} \mathrm{m}^{-2} \mathrm{~s}^{-1}$ were found in June $2012\left(-0.37 \mathrm{nmol} \mathrm{m}^{-2} \mathrm{~s}^{-1}\right)$ and August $2011\left(-0.31 \mathrm{nmol} \mathrm{m}^{-2} \mathrm{~s}^{-1}\right)$, deposition fluxes of
$-0.45 \mathrm{nmol} \mathrm{m}^{-2} \mathrm{~s}^{-1}$ on 6 December 2009, 1 week after the start of continuous snow cover, were mainly caused by erratic nighttime fluxes but nevertheless passed all quality control criteria (Fig. 1).

In contrast to emission rates, which reached their maximum on days when the meadow was cut, peak VMRs in each year were generally found 1-2 weeks after the first and second cut, but also in November. The highest VMR was recorded in June 2012 (2.3 ppbv). Between 2008 and 

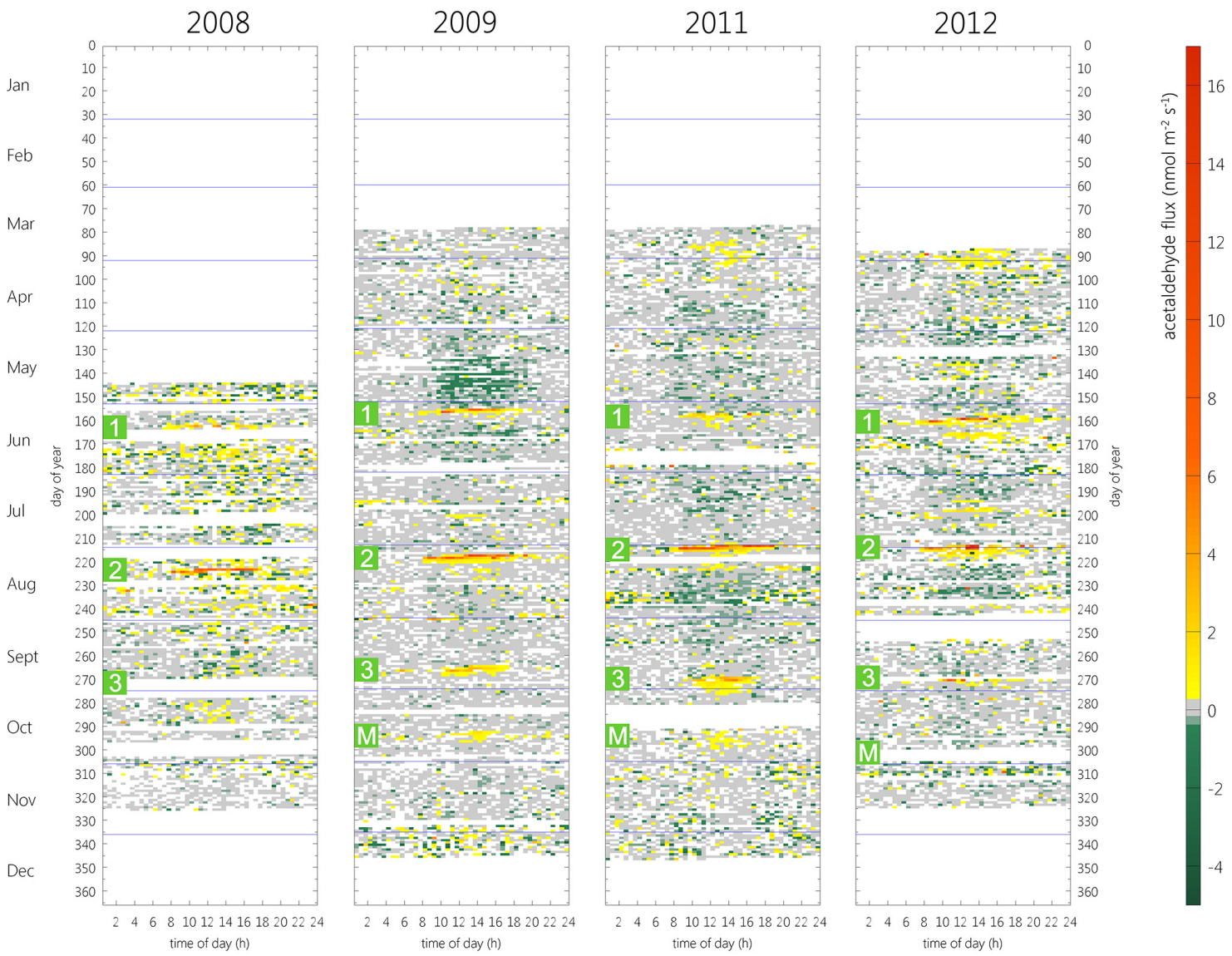

Figure 2. Half-hourly acetaldehyde fluxes over 4 years of VOC measurements. Numbers 1, 2 and 3 in green squares mark the first, second and third cutting of the meadow, respectively, while $M$ denotes manure spreading. Horizontal blue lines show the start and end of months.

2012 and including management, the daily average VMR of acetaldehyde was above $0.5 \mathrm{ppbv}$ on 379 days $(45 \%$ of all recorded days).

Highest PAR values were similar in all 4 years, ranging from 663.7 in 2011 to $688.7 \mu \mathrm{mol} \mathrm{m}^{-2} \mathrm{~s}^{-1}$ in 2008 . Yearly average air temperatures of between 6.7 (2012) and $7.1^{\circ} \mathrm{C}$ $(2008,2011)$ were close to the $2001-2007$ average of $6.7^{\circ} \mathrm{C}$ at the same site. The highest daily average temperature was recorded at the end of June $2012\left(23.5^{\circ} \mathrm{C}\right)$, the lowest at the beginning of February $2012\left(-17.3^{\circ} \mathrm{C}\right)$ (Fig. 1). Halfhourly temperatures peaked at $32.5^{\circ} \mathrm{C}$ on 30 June 2012 , the lowest value was recorded on 6 February $2012\left(-22.4^{\circ} \mathrm{C}\right)$. On days where VOC measurements were performed, the average daily air temperature was between $-3.5-23.5^{\circ} \mathrm{C}$. Soil temperature at a depth of $5 \mathrm{~cm}$ was naturally dampened compared to air temperature, peaking at $22.1^{\circ} \mathrm{C}$ in June 2008 (Fig. 1). During winter months, soil temperatures were typically around zero, with the exception of January 2008 when temperatures fell as low as $-2.8^{\circ} \mathrm{C}$ on a daily average timescale.

Soil water content exhibited a similar pattern in all 4 years. Generally, peak values of up to $0.46 \mathrm{~m}^{3} \mathrm{~m}^{-3}$ were found around snow melt, after which SWC continually decreased to values as low as $0.08 \mathrm{~m}^{3} \mathrm{~m}^{-3}$ by mid-May $(2008,2011)$ or start of June $(2009,2012)$, a decline only temporarily interrupted by rain events. During the second half of the year, water content increased steadily with each precipitation event. Precipitation ranged between 499 (2012) and 648 (2008) $\mathrm{mm}$ $\mathrm{yr}^{-1}$, well below the 2001-2007 average of $765 \mathrm{~mm} \mathrm{yr}^{-1}$. During the measurement campaigns, rain was recorded on 77 (2008), 124 (2009), 97 (2011) and 81 (2012) days (Fig. 1).

On average, relative humidity was around $80 \%$, with the lowest value of $43 \%$ at the end of April 2012. Naturally, vapor pressure deficit was highest during warmer months between April and August with average values around $0.5 \mathrm{kPa}$ and reached peak values of $1.5 \mathrm{kPa}$ on 2 days at the end of May 2008. GAI was close to zero after snowmelt, reached $7.1-7.8 \mathrm{~m}^{2} \mathrm{~m}^{-2}$ right before the first cut and was then reduced to $1.3-2.0 \mathrm{~m}^{2} \mathrm{~m}^{-2}$ due to harvesting. Maximum values before the second and third cut decreased compared to the first cut and were in the range of $6.7-7.1$ and $5.1-6.3 \mathrm{~m}^{2} \mathrm{~m}^{-2}$, respectively. After the third cut GAI first increased and later decreased. 


\subsection{Inter-annual variability}

Figure 2 shows half-hourly fluxes during the 4 years of measurements. For each year highest fluxes of acetaldehyde were recorded on the day of the second cut or 1 day later with peak values of $11.0-16.5 \mathrm{nmol} \mathrm{m}^{-2} \mathrm{~s}^{-1}$. Including days influenced by management, deposition from the atmosphere to the meadow was observed for $54 \%$ of all halfhourly acetaldehyde fluxes, strong uptake with fluxes below $-0.3 \mathrm{nmol} \mathrm{m}^{2} \mathrm{~s}^{-1}$ for $8 \%$. During undisturbed conditions, $98 \%$ of all fluxes were between -1 and $1 \mathrm{nmol} \mathrm{m}^{-2} \mathrm{~s}^{-1}$.

The meadow acted as a net source of acetaldehyde in all 4 years (Fig. 3). The largest efflux was recorded in 2008 with an emission of $27.8 \mathrm{mg} \mathrm{C} \mathrm{m}^{-2}$ in 183 days, followed by 2012 (17.5 $\mathrm{mg} \mathrm{C} \mathrm{m}^{-2} / 239$ days). Lower emissions were observed for 2009 (7.4/269) and 2011 (9.9/270). Cumulative carbon emissions on days influenced by management events were substantial (Fig. 3). In 2008, $11.0 \mathrm{mg} \mathrm{C} \mathrm{m}^{-2}$ were emitted over a time period of 4 days that were influenced by two cutting events. 2009 and 2011 were similar: in both years all 3 cuts and the spreading of the manure were captured by the acetaldehyde measurements, resulting in 12 days influenced by anthropogenic actions that resulted in a total emission of 17.7 (2009) and 17.9 (2011) $\mathrm{mg} \mathrm{C} \mathrm{m}^{-2}$, whereby emissions as a direct result of manure spreading accounted for 1.6 and $0.9 \mathrm{mg} \mathrm{C} \mathrm{m}^{-2}$, respectively. Highest emissions as a direct consequence of management actions were found in 2012 (20.9 $\mathrm{mg} \mathrm{C} \mathrm{m}^{-2}$ over 9 days), although management dates were only partially (third cut) or not at all (manure spreading) covered by our measurements (Fig. 3). On a daily average scale, no deposition was observed on management days. When days with management influence were excluded from the analysis, only 2008 acted as a source of acetaldehyde $\left(16.8 \mathrm{~m} \mathrm{C} \mathrm{m}^{-2}\right)$, while all other years acted as a sink with cumulative deposition fluxes of -10.4 (2009), -8.0 (2011) and -3.5 (2012) $\mathrm{mg} \mathrm{C} \mathrm{m}^{-2}$.

With the exception of 2008, distinct time periods characterized by consecutive days with net acetaldehyde uptake were observed in each year (Fig. 3). For example, starting on 15 April 2009 the meadow acted as a strong sink for acetaldehyde over the next 49 days, divided into two stages distinguished by uptake rates. During the first 28 days until 12 May 2009 a total of $-3.0 \mathrm{mg} \mathrm{C} \mathrm{m}^{-2}$ was transported to the meadow, a process only shortly interrupted by 2 days of emission fluxes and resulting in an average uptake rate of $-0.11 \mathrm{mg} \mathrm{C} \mathrm{m}^{-2} \mathrm{~d}^{-1}$. The speed of this deposition process nearly tripled to $-0.30 \mathrm{mg} \mathrm{C} \mathrm{m}^{-2} \mathrm{~d}^{-1}$ over the following 21 days for a cumulative total of $-6.40 \mathrm{mg} \mathrm{C} \mathrm{m}^{-2}$ until 2 June 2009, 2 days before the first cut. A very similar period was found over 47 days between 20 April and 5 June 2011, 1 day before the first cut, when $-4.57 \mathrm{mg} \mathrm{C} \mathrm{m}^{-2}$ were transported to the meadow $\left(-0.10 \mathrm{mg} \mathrm{C} \mathrm{m}^{-2} \mathrm{~d}^{-1}\right)$.

These periods were not restricted to the weeks leading up to the first cut, but were also found throughout the rest of the year. For example, notable periods of ac- etaldehyde uptake were found in June and July. Starting on 19 June 2009 and spanning a period of 17 days with acetaldehyde measurements until 10 July 2009 , average deposition fluxes of $-0.08 \mathrm{mg} \mathrm{C} \mathrm{m}^{-2} \mathrm{~d}^{-1}$ were recorded. Between 29 June and 30 July 2011, 2 days before the second cut, carbon was transported to the meadow at a rate of $-0.12 \mathrm{mg} \mathrm{C} \mathrm{m}^{-2} \mathrm{~d}^{-1} .1$ year later a similar period was observed between 25 June and 11 July 2012 with average deposition fluxes of $-0.22 \mathrm{mg} \mathrm{C} \mathrm{m}^{-2} \mathrm{~d}^{-1}$. Strong uptake was also recorded between 27 August-19 September 2011 $\left(-0.13 \mathrm{mg} \mathrm{C} \mathrm{m}^{-2} \mathrm{~d}^{-1}\right), 27$ April-7 May $2012(-0.23)$ and 9 August-16 August $2012(-0.31)$.

\subsection{Management influence}

Figure 4 shows the effect of cutting and manure spreading on half-hourly acetaldehyde VMRs and fluxes. Generally, fluxes were around zero directly before the management. The cutting of the meadow caused a sudden burst of acetaldehyde emissions from the meadow that reached a maximum on the day of the cut or 1 day later, and fluxes remained elevated for between 2 (first cut) and 5 days (second cut) after the cut.

The second cut of the meadow took place at the end of July or beginning of August and resulted in the strongest emission fluxes and longest observable management influence on acetaldehyde (Fig. 4). Maximum fluxes were found between $11.0-16.5 \mathrm{nmol} \mathrm{m}^{-2} \mathrm{~s}^{-1}$ on the day of the cut, remained equally high 1 day later (9.6-16.4), decreased sharply the following day (1.9-3.1) and subsequently leveled off to reach pre-cut, close-to-zero fluxes by day 5 after the cut. Emissions caused by the first or third cutting of the meadow were lower, with maximum emissions of 5.3-14.7 and 4.3$8.4 \mathrm{nmol} \mathrm{m}^{-2} \mathrm{~s}^{-1}$ on the day of cutting, respectively, and dropped off more rapidly after the management event. In most years no cutting influence could be seen by day 3 after the cut. One exception to this pattern was the third cut in September 2011, when the cut grass was left on the field for drying and maximum emissions were observed during the turning of the grass in the afternoon 1 day after the cut. During this event, acetaldehyde continued to exhibit a clear diurnal emission cycle until 5 days after the harvesting (Fig. 4). Often, peak emissions were observed during the turning of the hay or immediately after all grass was collected from the field. For example, the first cut in 2011 started at 9 a.m. and maximum emissions during the harvesting were observed about 1 hour later $\left(2.5 \mathrm{nmol} \mathrm{m}^{-2} \mathrm{~s}^{-1}\right)$. The hay was left on the field, turned at 12 p.m. (3.5) and collected at 3 p.m. Maximum emissions were then observed at 4 p.m., immediately after all grass was removed from the field (6.8) (Fig. 4). This pattern was even more pronounced in 2012, when maximum emissions during the first cut were relatively low (2.2). However, acetaldehyde increased considerably 1 day later during the turning of the hay at 11:30 a.m. (14.7), then decreased sharply until 1 p.m. (4.3), increased significantly during the 


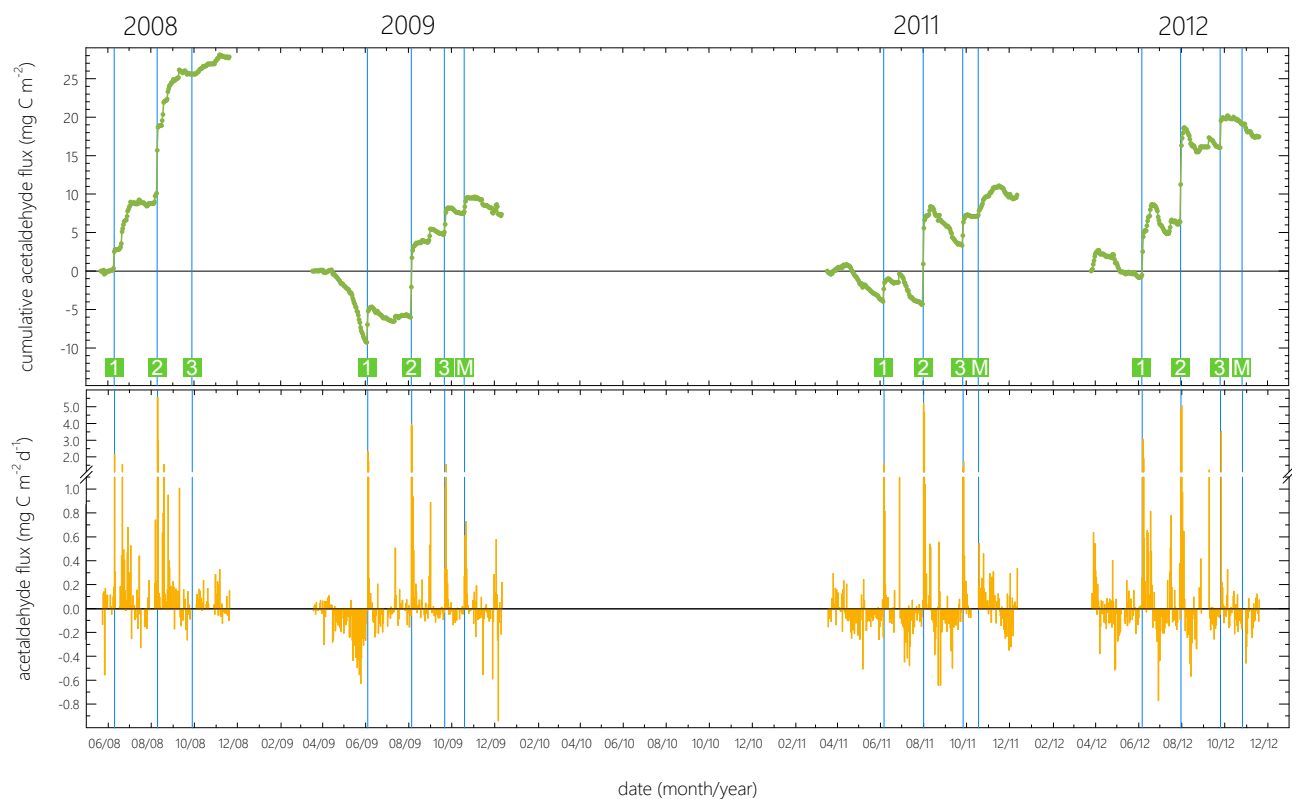

Figure 3. Cumulative and daily average acetaldehyde fluxes over 4 years of VOC measurements. Vertical lines show management dates, numbers 1, 2 and 3 in green squares mark the first, second and third cutting of the meadow, respectively, while $M$ denotes manure spreading.

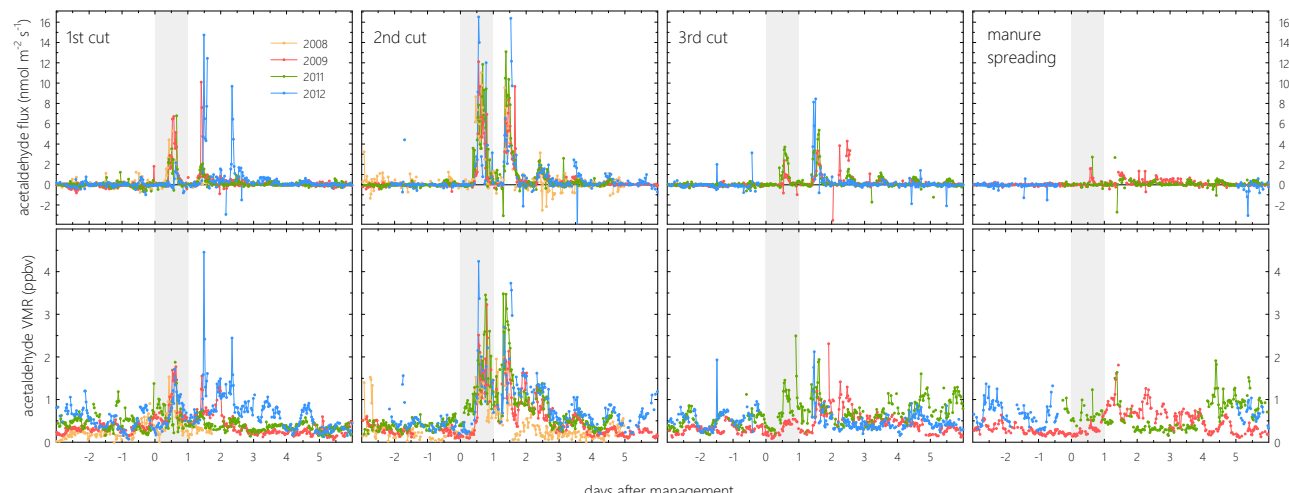

Figure 4. The influence of management events on acetaldehyde fluxes and volume mixing ratios (VMR) during 4 years of VOC measurements, the filled rectangle marks the day of the management action.

collection of the hay at 2 p.m. (12.4) and then immediately dropped off to zero at 3 p.m. (Fig. 4, see also Sect. 4.1).

The spreading of manure was only covered by measurements in 2009 and 2011, where emissions between 1.6$2.7 \mathrm{nmol} \mathrm{m}{ }^{-2} \mathrm{~s}^{-1}$ were observed, about 1 order of magnitude higher than maximum fluxes 1 day earlier during undisturbed conditions (Fig. 4). In 2011, the spreading of manure on the meadow was split over 2 days and started on 18 October. On the first day, fluxes increased rapidly to $2.7 \mathrm{nmol} \mathrm{m}^{-2} \mathrm{~s}^{-1}$ when the manure was brought out directly in the footprint at 3 p.m. Acetaldehyde fluxes started to exhibit a clear diurnal cycle for several days thereafter, with peak emissions of $2.7 \mathrm{nmol} \mathrm{m}^{-2} \mathrm{~s}^{-1}$ at 7 a.m. on 19 October during the thawing of the nightly frost-cover on plants and manure (Fig. 4).
Unfortunately, in 2011 the days directly before fertilization were not covered by VOC measurements.

High emission fluxes of acetaldehyde were generally accompanied by high volume mixing ratios. Maximum halfhourly VMRs of $4.2 \mathrm{ppbv}$ were registered on the day of the second cut 2012, the same day when also the highest emission flux values were measured (Fig. 4). After cutting events, maximum concentrations of acetaldehyde continued to remain elevated over several days, gradually decreasing to precut values. 


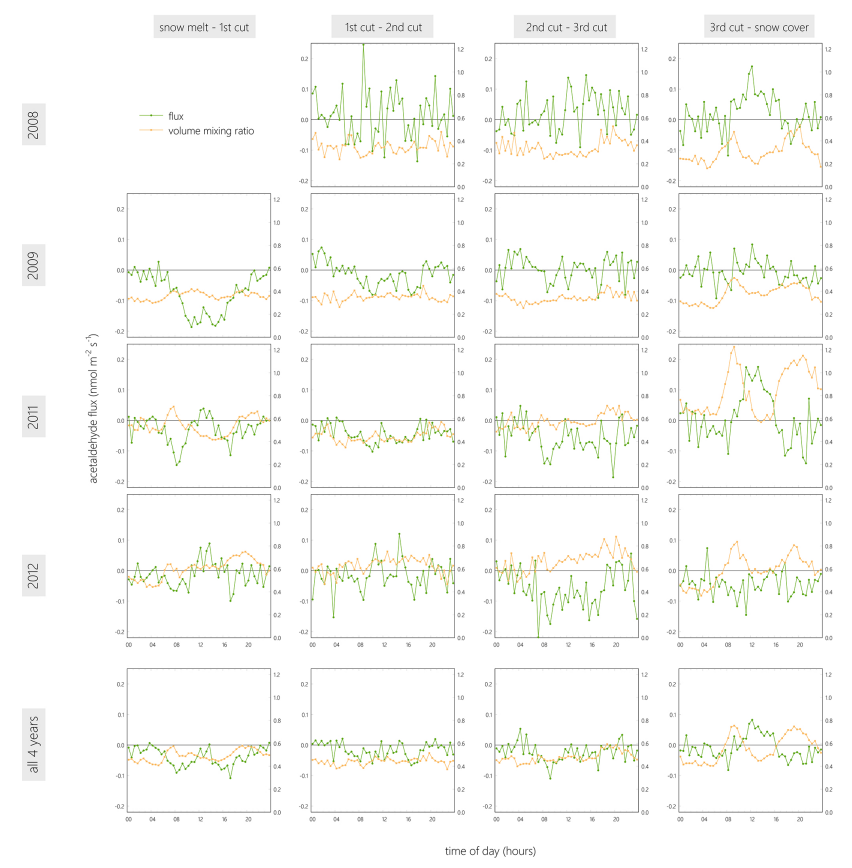

Figure 5. Diurnal cycles of acetaldehyde fluxes and volume mixing ratios (VMR) during different time periods over 4 years of VOC measurements. Management data were excluded from the analysis.

\subsection{Seasonal variability}

Figure 5 shows the diurnal course of acetaldehyde fluxes and VMRs before, in-between and after management events in all 4 investigated years.

The most distinct uptake was observed in 2009 after snowmelt and before the first cut, when acetaldehyde deposition to the meadow started early in the morning during a period of increasing VMRs and lasted until midnight, maximum uptake was $-0.19 \mathrm{nmol} \mathrm{m}^{-2} \mathrm{~s}^{-1}$ around noon. A clear diurnal uptake pattern characterized by two uptake peaks was observed in 2011, when the daily maximum deposition flux of $-0.15 \mathrm{nmol} \mathrm{m}^{-2} \mathrm{~s}^{-1}$ was recorded in the morning, shortly after the maximum VMR of $0.71 \mathrm{ppb}$ (Fig. 5). After a period of close-to-zero fluxes and low VMRs around noon, uptake of acetaldehyde started again in the afternoon when acetaldehyde concentrations started to increase. The exchange pattern was similar but less distinct in 2012, when local maxima and minima for both fluxes and VMRs were often observed during the same half-hour or within an hour (Fig. 5). On average, flux and VMR patterns between snow melt and the first cut of the year exhibited a clear diurnal cycle, whereby highest uptake rates before noon were recorded shortly after the daily maximum acetaldehyde concentration and in the afternoon during rising VMRs.

In the period after the first and before the second cut, low uptake rates were constantly recorded during daytime in 2009 and 2011, while exchange patterns during the other 2 years showed higher variability (Fig. 5). The average 4 yr di- urnal cycle shows a tendency towards weak acetaldehyde deposition during daytime and stable VMRs around $0.40 \mathrm{ppbv}$.

Later in the year after the second and before the third cut, acetaldehyde showed strong deposition fluxes of up to $-0.22 \mathrm{nmol} \mathrm{m}^{-2} \mathrm{~s}^{-1}$ in 2012 and exhibited a distinct diurnal cycle, which was in strong contrast to 2008 and 2009 when fluxes were fluctuating around zero. 2011 was similar to 2012, with clear deposition before noon and in the afternoon, and fluxes close to zero around noon (Fig. 5). Over all 4 years, the meadow acted as a sink for acetaldehyde, whereby uptake started in the morning and continued until the evening, with maximum deposition fluxes of $-0.11 \mathrm{nmol} \mathrm{m}^{-2} \mathrm{~s}^{-1}$ before noon (Fig. 5).

The diurnal course of VMRs after the third cut and before snow cover was similar to the period before the first cut, with two daily VMR maxima and a local minimum around noon, but flux patterns were rather different with clear acetaldehyde emission at midday. Highest emission rates of 0.17 and $0.18 \mathrm{nmol} \mathrm{m}^{-2} \mathrm{~s}^{-1}$ were recorded in 2008 and 2011, respectively, when VMRs were close to their minimum after a sharp decrease following the morning peak (Fig. 5). On average, maximum deposition fluxes were recorded both in the morning and evening, when VMRs were close to their maximum.

\subsection{Environmental controls}

In order to analyze the drivers behind observed acetaldehyde fluxes, a multiple linear regression was performed using daily average values for days with deposition (group $f-$, includes days with daily average fluxes $<-0.03 \mathrm{nmol} \mathrm{m}^{-2} \mathrm{~s}^{-1}$ ), emission $\left(f+,>0.03 \mathrm{nmol} \mathrm{m}^{-2} \mathrm{~s}^{-1}\right)$ and around-zero $(f 0$, between -0.03 and $0.03 \mathrm{nmol} \mathrm{m}^{-2} \mathrm{~s}^{-1}$ ) fluxes as well as for the different time periods before, in-between and after cutting events (Table 1).

Ancillary data explained $15 \%$ of the observed acetaldehyde exchange when data of all 4 years were pooled together and $21-26 \%$ when $4 \mathrm{yr}$ data were pooled for specific time periods. During the same time periods but in single years, between $21-85 \%$ of the acetaldehyde flux pattern could be explained, whereby the regression was significant $(p<0.05)$ in 11 of 14 time periods and highly significant $(p<0.001)$ once, before the first cut in 2009 during the period of highest acetaldehyde deposition (Table 1, Fig. 5).

Among the collected parameters only 2 - the net ecosystem $\mathrm{CO}_{2}$ exchange (NEE) and acetaldehyde VMR - were highly significant during at least 1 time period, while $T_{\text {air }}$ was the only parameter that was not significant in any period (Table 1). When all data were pooled, NEE had the highest positive partial correlation (PC) among all parameters in combination with a high tolerance value. Its influence was similar on days with close-to-zero fluxes (group $f 0$ ), but diminished clearly on days with acetaldehyde uptake $(f-)$ or emission $(f+)$. Over the course of the vegetation period, PCs and tolerance values of NEE increased towards the end of the year (Table 1). The other two ecosystem fluxes, latent evaporation 


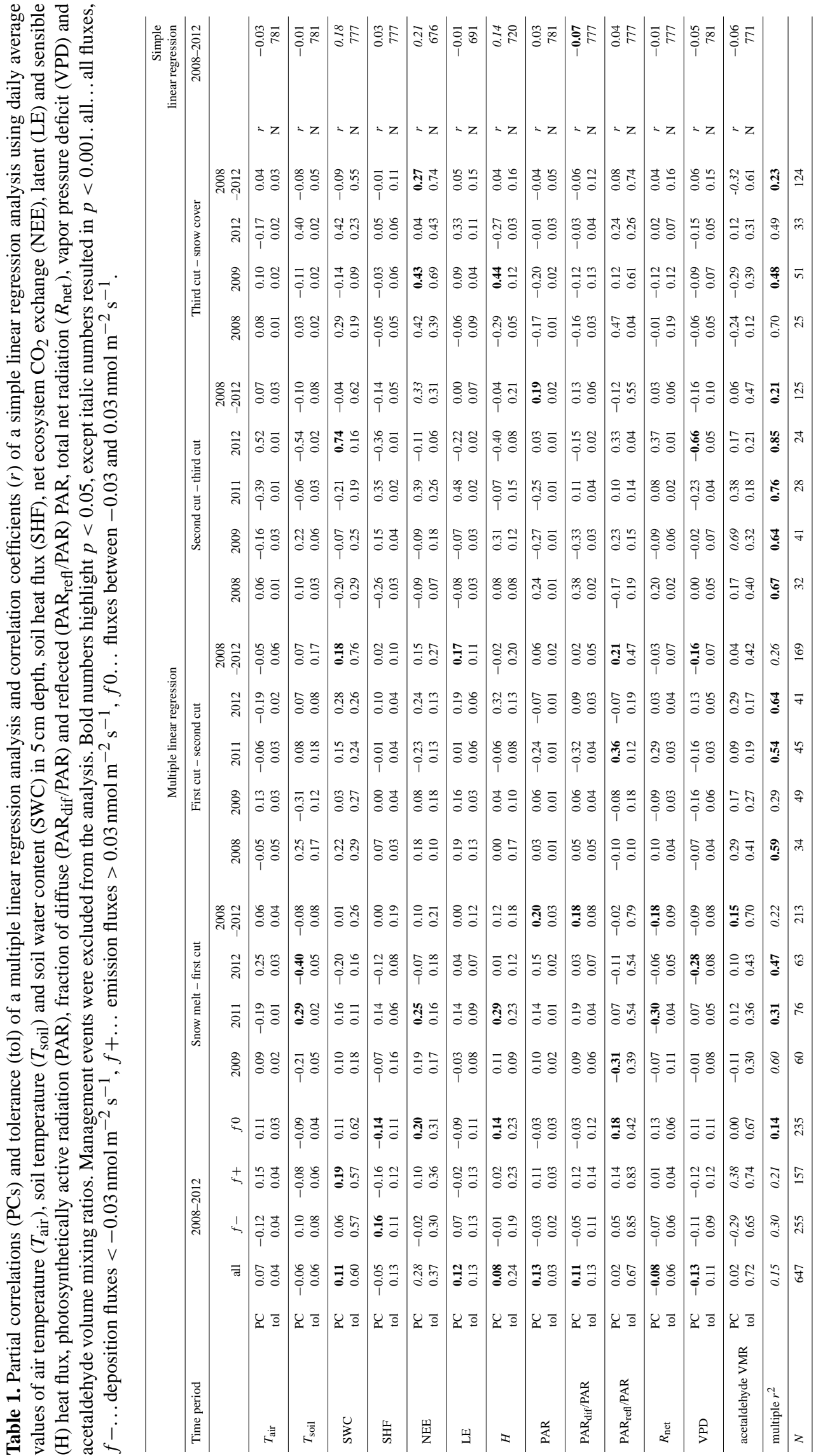


(LE) and sensible heat flux $(H)$, were also significant on a $4 \mathrm{yr}$ scale, but their respective PC with acetaldehyde fluxes was considerably lower when compared to NEE. $H$ was positively correlated with acetaldehyde emission $(f 0)$ and significant during time periods in single years whenever NEE was also significant (Table 1). Due to the bidirectional influence of LE and $H$, their PCs often changed in sign between years, often resulting in very low PCs when data were pooled for specific time periods. The proportion of unique variance relative to the total variance of acetaldehyde fluxes accounted for by all ecosystem fluxes combined (NEE, LE and $H$ ) over all 4 yr was $9 \%$.

In contrast to NEE, acetaldehyde VMR was characterized by a highly significant negative and positive $\mathrm{PC}$ on uptake and deposition days, respectively, but its PC was very low when all data were pooled and on days with fluxes around zero. During most of the vegetation period and especially at the beginning, partial correlations were found to be positive, but changed in sign towards the end of the measurement campaign after the third cut (Table 1). However, a highly significant positive PC was found in 2009 between the second and third cut, a period of around-zero fluxes (Fig. 5).

Radiation variables showed significant correlations especially at the start of the vegetation period before the first cut, and none of the radiation parameters yielded significant results after the third cut. Although PAR, PAR $_{\text {dif }} / \mathrm{PAR}$ and $R_{\text {net }}$ were significant on a $4 \mathrm{yr}$ scale, they explained only $3 \%$ of the total acetaldehyde flux variance when combined (Table 1). $\mathrm{PAR}_{\text {reff }} / \mathrm{PAR}$ had little influence when all data were pooled, but had a high and significant negative PC during the period when acetaldehyde deposition fluxes were highest, before the first cut in 2009 (Table 1, Fig. 5).

On a $4 \mathrm{yr}$ scale, SWC had a positive PC with acetaldehyde emission and was characterized by high tolerance values, underlining its unique contribution to the regression equation. It also had the highest PC among all parameters in a multiple linear regression, found in a period of low acetaldehyde uptake between the second and third cut in 2012 (Table 1, Fig. 5). The PC between SHF and acetaldehyde VMRs was positive on deposition days $(f-)$ and negative on emission days $(f+)$. Although SHF was not significantly correlated with acetaldehyde exchange over the course of the vegetation period, its PCs were considerably higher between the second and third cut than during other time periods (Table 1). $T_{\text {soil }}$ was the only soil parameter that was not significant on any of the $4 \mathrm{yr}$ scales, but in the time period between snow melt and first cut of 2 consecutive years, when its PC changed from positive to negative. The negative PC found for vapor pressure deficit (VPD) when all data were pooled was very similar to values found throughout the 2 years. Its highest PC was observed in 2012 in the period between the second and third cut, when uptake strongly increased with VPD.

A simple linear regression analysis resulted in SWC, NEE and $H$ having highly significant positive correlations, which were very similar in magnitude to their respective PCs (Ta-

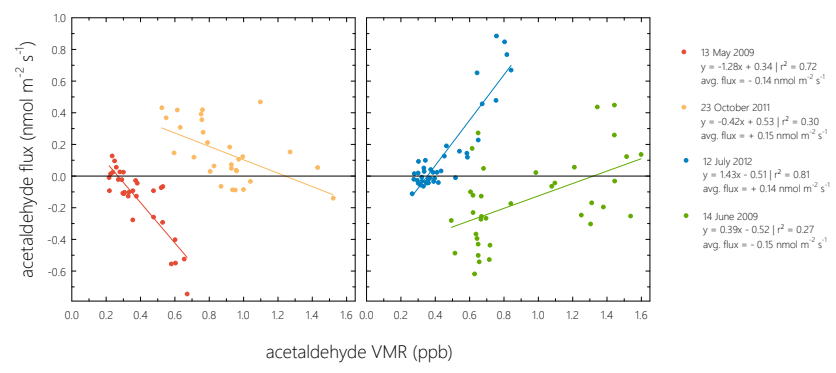

Figure 6. Four days with different relationships between halfhourly acetaldehyde volume mixing ratio (VMR) and flux including linear regression lines, showing negative and positive correlation between the 2 parameters on days with net emission and net deposition of acetaldehyde.

ble 1). No significant correlations were found for all other parameters with the exception of $\mathrm{PAR}_{\mathrm{dif}} / \mathrm{PAR}$, which in contrast to its $\mathrm{PC}$ was negatively correlated and significant.

\subsection{Compensation point}

As shown before, the correlation between acetaldehyde VMRs and fluxes based on daily average values was not constant, changed over the course of a single year as well as between years and was generally weak or statistically not significant (Table 1). Although the regression analyses could not reveal a consistent relationship between the two variables, it indicated that a link between VMRs and fluxes existed and that its strength varied over time. This changing relationship was also observed on single days when looking at half-hourly data for both parameters. Figure 6 depicts 4 days where the correlation between VMR and flux was either negative or positive, with both cases resulting in either daily net emission or uptake of acetaldehyde, showing that a negative correlation on a certain day did not necessarily translate into acetaldehyde deposition.

In order to investigate controls on a possible compensation point for acetaldehyde, $C^{*}$ was quantified on two different time scales by calculating the zero-crossing of the linear regression between acetaldehyde VMR as the independent variable and flux as the dependent parameter with the $x$ axis.

First we examined the relationship between daily average values of acetaldehyde VMRs and fluxes in 7-day windows, whereby management influence was excluded from the analysis. The different relationships between the 2 parameters as shown in Fig. 6 for half-hourly data on single days were also observed for daily average data in 7-day windows (Fig. 7a). During certain weeks in each year, slope $k$ of the regression equation was negative and indicated uptake of acetaldehyde with increasing VMR (Fig. 7). However, slope $k$ was found to be positive during other time periods, suggesting a release of acetaldehyde with increasing VMRs. In both of these groups the goodness of fit varied greatly over the season. Therefore, Fig. 7a depicts compensation points for all 7-day windows 


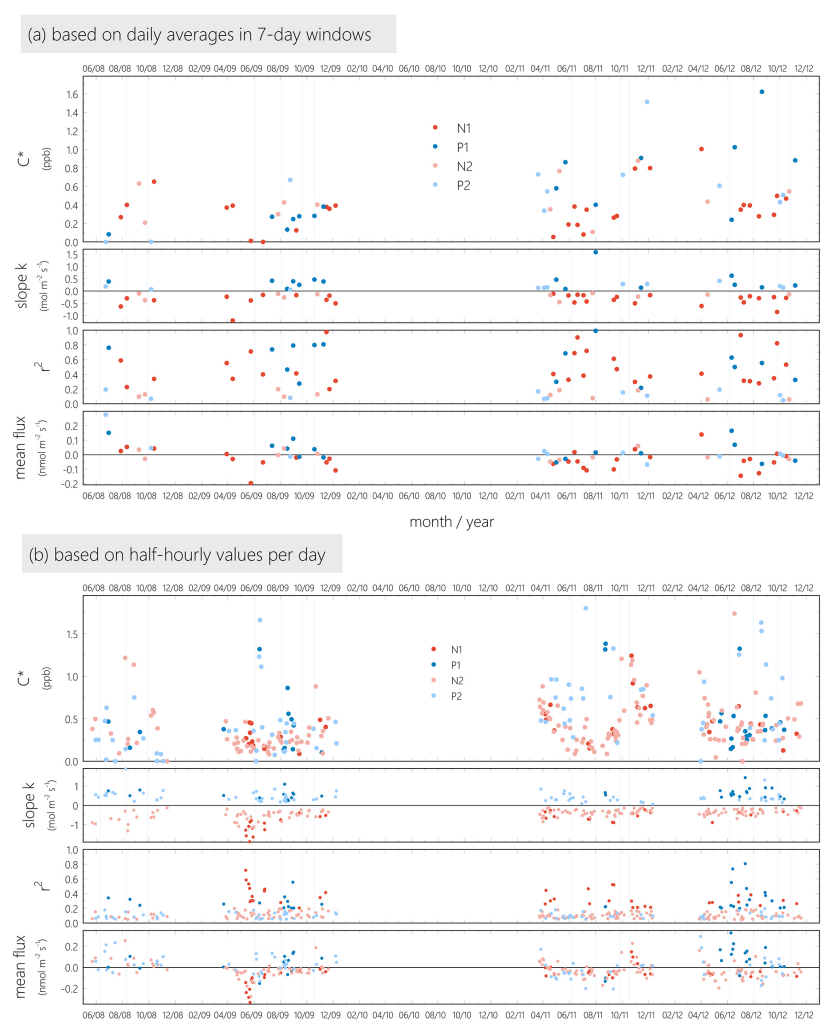

Figure 7. Results of a simple linear regression between acetaldehyde VMR as the independent variable and flux as the dependent parameter, quantifying the compensation point $\left(C^{*}\right)$, slope $k, r^{2}$ and the respective acetaldehyde flux on two different time scales. Panel (a) shows $C^{*}$ calculated from daily average values in 7-day windows when a minimum of 4 days was present in each window. Panel (b) illustrates $C^{*}$ and corresponding parameters calculated from half-hourly values per day. Colors represent direction of correlation and goodness of fit between acetaldehyde VMRs and fluxes: N1...negative slope, $r^{2}>0.2, \mathrm{~N} 2 \ldots$ negative slope, $0.05<r^{2}<0.2$, P1 . p positive slope, $r^{2}>0.2, \mathrm{P} 2 \ldots$ positive slope, $0.05<r^{2}<0.2$. All management data were excluded from the analysis.

where the regression between VMR and flux resulted in an either positive $(\mathrm{P})$ or negative $(\mathrm{N})$ slope $k$, both groups further distinguished by the goodness of fit. In total, 235 7-day periods were investigated, 66 of which passed all quality criteria and are displayed in Fig. 7a. The average $C^{*}$ in periods with negative $k$ was 0.36 and $0.46 \mathrm{ppbv}$ in weeks with high $r^{2}\left(>0.2\right.$, group N1) and low $r^{2}$ (between 0.05 and 0.2 , group N2), respectively. For weeks with a positive relationship (groups P1, P2) between acetaldehyde VMR and flux, average $C^{*}$ was found at $0.55 \mathrm{ppbv}$. During other periods the goodness of fit was considerably lower, but nevertheless resulted in similar values for $C^{*}$.

By performing a simple linear regression analysis using half-hourly values of acetaldehyde VMRs and fluxes, it was possible to calculate $C^{*}$ for each day (Fig. 7b). In total 691 days were analyzed, on 67 days of which $r^{2}$ between VMR and flux was found above 0.2 (groups $\mathrm{P} 1, \mathrm{~N} 1$ ). Slope $k$ between the 2 parameters was negative on 188 days, positive on 102 days. No $C^{*}$ was calculated for 401 days due to the goodness of fit between acetaldehyde VMR and flux being below 0.05 . Generally, $C^{*}$ was very similar to the values calculated in 7-day windows. When the slope $k$ was negative, the compensation point was on average 0.41 and $0.40 \mathrm{ppbv}$ with high and low $r^{2}$, respectively. Periods with a positive relationship between VMR and flux resulted in $C^{*}$ average values of 0.49 and 0.54 ppbv (Fig. 7b).

The best positive relationship between half-hourly acetaldehyde concentration values and fluxes was found on 12 July $2012\left(r^{2}=0.81\right)$, the best negatively correlated fit was found on 13 May $2009\left(r^{2}=0.72\right.$, Fig. 6). $C^{*}$ on days with negative slopes was relatively constant in all 4 years with the exception of 2011, when the compensation point decreased linearly $\left(r^{2}=0.67\right)$ from over $0.70 \mathrm{ppbv}$ at the end of March to $0.11 \mathrm{ppbv}$ right before the second cut, after which it increased again to values of up to $1.24 \mathrm{ppbv}$ in October (Figs. 6, 7b). Slope $k$ was strongly negative during a period of high uptake at the end of May 2009 with values as low as $-1.87 \mathrm{~mol} \mathrm{~m}^{-2} \mathrm{~s}^{-1}$. When negative, slope $k$ was found between -0.5 and $0 \mathrm{~mol} \mathrm{~m}^{-2} \mathrm{~s}^{-1}$ on a total of 129 days over all 4 years. Similarly, days with strongly positive slopes were mainly found during periods of acetaldehyde emission, for example right after the first cut in 2012 (Fig. 7b). However, the occurrence of a negative slope did not necessarily result in uptake of acetaldehyde (Figs. 6, 7b).

Figure $7 \mathrm{~b}$ showed that finding a clear relationship between half-hourly acetaldehyde VMRs and fluxes over a longer time period, for example between the first and second cut, posed a difficult task, as it was changing constantly. The relationship between VMRs and fluxes became clearer when looking at half-hourly bin averages of both parameters during different times of the year (Fig. 8). In addition, this approach enabled the calculation of $C^{*}$ by inter- or extrapolating the values of the two bins closest to the zero line and looking at the zero-crossing with the $x$ axis. During different time periods, $C^{*}$ was found between 0.05 (in the period snowmelt - first cut) and 0.19 ppbv (second-third cut, Fig. 8a). When all data were pooled, the compensation point was $0.13 \mathrm{ppbv}$ (Fig. 8b).

In addition, Fig. $8 \mathrm{c}$ investigates the relationship between binned VMR and flux in the four groups previously established in Fig. 7. For days where the relationship between half-hourly values of VMRs and fluxes yielded a negative correlation with $r^{2}>0.2$ (group N1, Fig. 7b) the compensation point was $0.10 \mathrm{ppbv}$, and $0.09 \mathrm{ppbv}$ when $r^{2}$ was between 0.05 and 0.2 (N2, Fig. 8c). On days with a positive slope $k$ (Fig. 7b) the relationship between bin averaged VMRs and fluxes was less clear. For high $r^{2}$ (P1), emission fluxes increased linearly with VMRs above a concentration of $0.54 \mathrm{ppbv}$, while acetaldehyde exchange fluctuated around zero at VMRs below (Fig. 8c). In group P2, deposition fluxes 

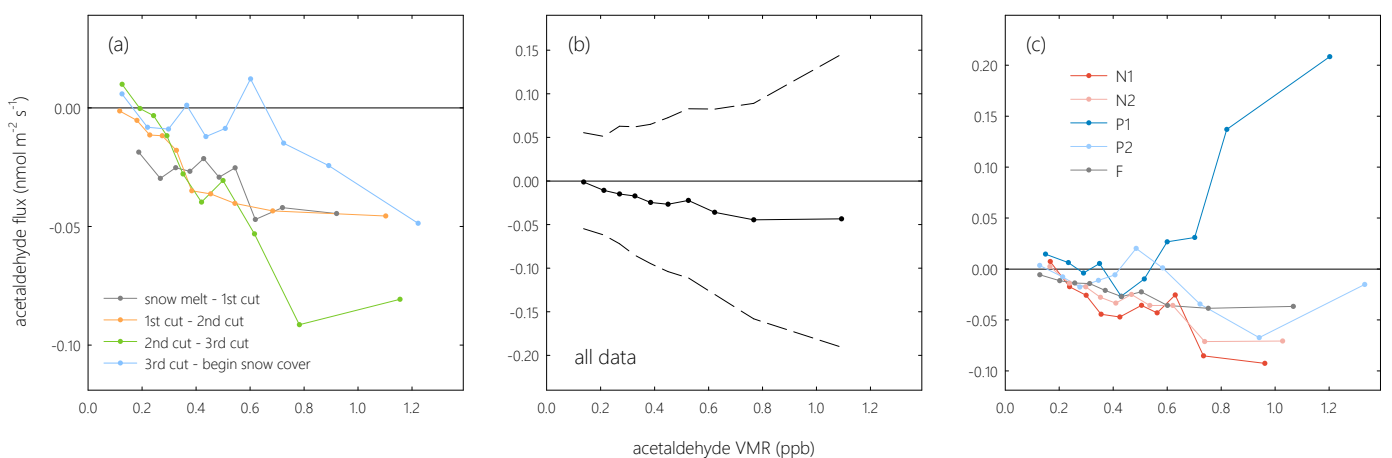

Figure 8. Bin averages of half-hourly acetaldehyde volume mixing ratio (VMR) and flux (a) during different time periods and over all 4 years (551-725 values per bin), (b) using all available data from all 4 years (2542 values per bin) and (c) in groups defined by the direction of correlation and goodness of fit between half-hourly acetaldehyde VMRs and fluxes: N1... negative slope, $r^{2}>0.2$, N2...negative slope, $0.05<r^{2}<0.2, \mathrm{P} 1 \ldots$ positive slope, $r^{2}>0.2$, P2 . positive slope, $0.05<r^{2}<0.2, F \ldots$ zero slope, $r^{2}<0.05$. All management data were excluded form the analysis.

were observed above $0.59 \mathrm{ppbv}$ (Fig. 8c). On days with no clear relationship $\left(r^{2}<0.05\right.$ group F) between VMR and flux on a half-hourly scale, $C^{*}$ was 0.06 ppbv.

Figures 7-8 show that the relationship between VMRs and fluxes is complex and that the correlation between the 2 parameters can be both negative and positive. For the purpose of modeling acetaldehyde fluxes at our study site it is important to better understand the relationship between acetaldehyde concentration and flux, in particular whether a significant correlation between these 2 parameters on a given day exists, and if it is positive or negative. Therefore, an ANOVA was performed to determine significant environmental differences between the groups established in Fig. 7b. The analysis revealed that only groups N1 and P1 were significantly different from each other, with $T_{\text {soil }}$ and SWC both being higher in $\mathrm{P} 1\left(15.7^{\circ} \mathrm{C}\right.$ and $0.29 \mathrm{~m}^{3} \mathrm{~m}^{-3}$, respectively) than in $\mathrm{N} 1\left(12.1^{\circ} \mathrm{C}\right.$ and $\left.0.24 \mathrm{~m}^{3} \mathrm{~m}^{-3}\right)$. Daily average values of both parameters and in both groups are illustrated in Fig. 9.

Table 2 examines to what extent measured ancillary data can explain $C^{*}$ and slope $\mathrm{k}$, both resulting from the analysis in Fig. 7b, in forward stepwise regression analyses. Generally, results for N1 and P1 can be regarded as the most reliable, as both groups are characterized by a relatively high correlation between VMR and flux.

Among the different groups between $66-75 \%$ of the $C^{*}$ variance could be explained, whereby acetaldehyde VMR was highly significant and positively correlated with $C^{*}$ in N1, N2 and P2, but was not used in P1, where instead VPD emerged as the most important regressor with the highest partial correlation of any parameter in the $C^{*}$ regression analysis. While SHF was an important predictor in N1 and not in P1, the opposite was the case for PAR. NEE was the only parameter that was used in the regression equation of both $\mathrm{N} 1$ and $\mathrm{P} 1$, being positive in the former group and negative in the latter, but not significant in either. Most significant variables were found for $\mathrm{N} 2$, where $T_{\text {air }}$ was positively, but

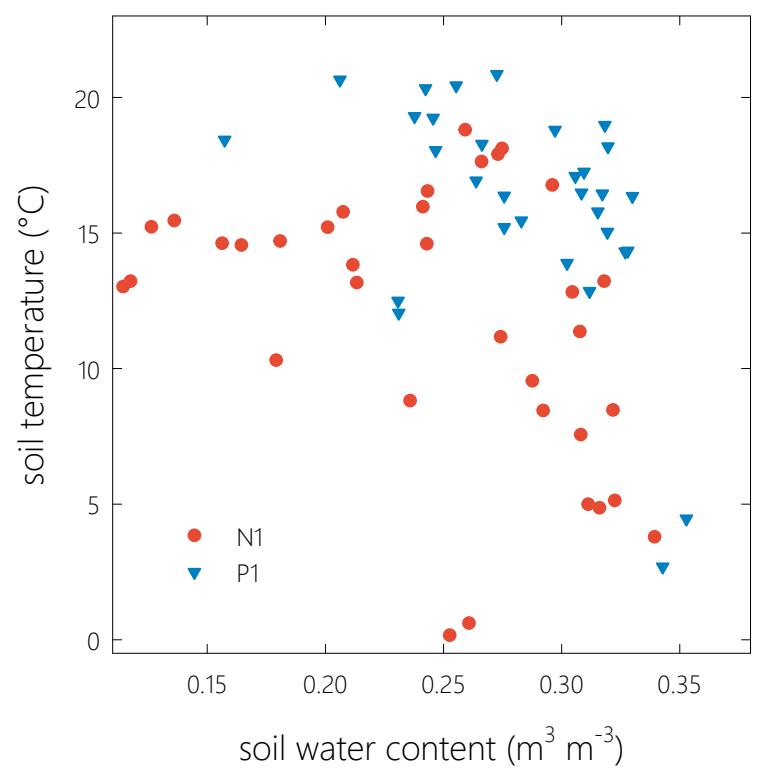

Figure 9. Daily average values of soil temperature $\left(T_{\text {soil }}\right)$ and soil water content (SWC) in two groups defined by the direction of correlation and goodness of fit between half-hourly acetaldehyde VMRs and fluxes, where N1... negative slope, $r^{2}>0.2$, $\mathrm{P} 1 \ldots$ positive slope, $r^{2}>0.2$. All management data were excluded from the analysis.

$T_{\text {soil }}$ negatively correlated with $C^{*}$, a significant difference to P2, where the 2 PCs changed in sign. Similarly, the PCs of both PAR and NEE were positive in N2, but negative in both $\mathrm{P} 1$ and P2. N2 was also the only group where the other two ecosystem fluxes, LE and $\mathrm{H}$, were significant (Table 2). Four parameters were not significant in any of the groups (SWC, $\left.\mathrm{PAR}_{\text {dif }} / \mathrm{PAR}, \mathrm{PAR}_{\text {reff }} / \mathrm{PAR}, R_{\text {net }}\right)$.

The regression analysis of slope $k$ resulted in substantial differences between groups $\mathrm{N}$ and $\mathrm{P}$. While the analysis resulted in only one variable being significant in P1 and P2, 
Table 2. Partial correlations of forward stepwise multiple linear regression analyses of the compensation point $\left(C^{*}\right)$ and slope $k$ calculated per day from half-hourly acetaldehyde VMR and flux values, using daily average values of air temperature $\left(T_{\text {air }}\right)$, soil temperature $\left(T_{\text {soil }}\right)$ and soil water content (SWC) in $5 \mathrm{~cm}$ depth, soil heat flux (SHF), net ecosystem $\mathrm{CO}_{2}$ exchange (NEE), latent (LE) and sensible (H) heat flux, photosynthetically active radiation (PAR), fraction of diffuse ( $\left.\mathrm{PAR}_{\text {dif }} / \mathrm{PAR}\right)$ and reflected $(\mathrm{PAR}$ refl $/ \mathrm{PAR}) \mathrm{PAR}$, total net radiation $\left(R_{\text {net }}\right)$, vapor pressure deficit (VPD) and acetaldehyde volume mixing ratios (VMR). Bold numbers highlight $p<0.05$, except italic numbers resulted in $p<0.001$. Groups represent direction of correlation and goodness of fit between acetaldehyde VMR and flux: N1...negative slope, $r^{2}>0.2$, N2...negative slope, $0.05<r^{2}<0.2$, P1 . positive slope, $r^{2}>0.2$, P2 . positive slope, $0.05<r^{2}<0.2$. All management data were excluded from the analysis.

\begin{tabular}{|c|c|c|c|c|c|c|c|c|}
\hline \multirow{2}{*}{$\begin{array}{l}\text { Dependent variable } \\
\text { Group }\end{array}$} & \multicolumn{4}{|c|}{$C^{*}$} & \multicolumn{4}{|c|}{ Slope $k$} \\
\hline & N1 & $\mathrm{N} 2$ & $\mathrm{P} 1$ & $\mathrm{P} 2$ & N1 & $\mathrm{N} 2$ & $\mathrm{P} 1$ & $\mathrm{P} 2$ \\
\hline Slope flux vs. VMR & \multicolumn{2}{|c|}{ negative } & \multicolumn{2}{|c|}{ positive } & \multicolumn{2}{|c|}{ negative } & \multicolumn{2}{|c|}{ positive } \\
\hline Correlation flux vs. VMR & high & low & high & low & high & low & high & low \\
\hline$T_{\text {air }}$ & -0.26 & 0.28 & & -0.26 & -0.54 & & & \\
\hline$T_{\text {soil }}$ & & -0.30 & & 0.31 & 0.60 & & 0.29 & \\
\hline SWC & & & & -0.15 & 0.49 & 0.31 & & \\
\hline SHF & 0.42 & -0.16 & & 0.06 & 0.30 & & & \\
\hline NEE & 0.33 & 0.34 & -0.34 & -0.37 & & -0.28 & & \\
\hline LE & & -0.20 & & & 0.49 & 0.10 & & \\
\hline $\mathrm{H}$ & 0.22 & 0.36 & & & 0.56 & & & \\
\hline PAR & & 0.25 & -0.59 & -0.24 & -0.78 & -0.28 & & -0.16 \\
\hline $\mathrm{PAR}_{\mathrm{dif}} / \mathrm{PAR}$ & & 0.15 & & 0.02 & -0.39 & -0.21 & & \\
\hline $\mathrm{PAR}_{\text {refl }} / \mathrm{PAR}$ & & & & & 0.47 & & & \\
\hline$R_{\text {net }}$ & & -0.09 & & & & 0.17 & & 0.21 \\
\hline VPD & & & 0.84 & 0.34 & 0.75 & & -0.42 & \\
\hline Acetaldehyde VMR & 0.69 & 0.73 & & 0.72 & 0.65 & 0.38 & & $\begin{array}{r}-0.30 \\
0.66\end{array}$ \\
\hline Multiple $r^{2}$ & 0.66 & 0.68 & 0.75 & 0.71 & 0.86 & 0.35 & 0.19 & 0.15 \\
\hline$N$ & 29 & 127 & 28 & 61 & 29 & 127 & 28 & 61 \\
\hline
\end{tabular}

9 and 5 parameters were found at $p<0.05$ for $\mathrm{N} 1$ and $\mathrm{N} 2$, respectively, explaining 86 and $35 \%$ of the observed total variance of slope $k$ between acetaldehyde VMRs and fluxes (Table 2). Similar to the $C^{*}$ analysis, VMR was an important predictor in all groups except in P1, where VPD was the most significant parameter and, in contrast to N1, positively correlated with slope $k$. Results in N1 and N2 were similar, with SWC and VMR being positively, PAR negatively correlated. The 2 temperature parameters $T_{\text {air }}$ and $T_{\text {soil }}$ were only significant in N1 and had a negative and positive PC with slope $k$, respectively. Other significant parameters in $\mathrm{N} 1$ with PCs similar to $T_{\text {soil }}$ were LE, $H$ and PAR $_{\text {refl }} / \mathrm{PAR}$. NEE and $\mathrm{PAR}_{\text {dif }} / \mathrm{PAR}$ were significant only in N2, while SHF and $R_{\text {net }}$ were not significant in any of the groups (Table 2).

\section{Discussion}

\subsection{Flux variability}

The present study shows that air temperature cannot explain ecosystem acetaldehyde fluxes at the present site. The influence of $T_{\text {air }}$ on observed flux patterns was statistically insignificant during each of the time periods shown in Ta- ble 1 and in addition virtually zero in a simple linear regression. Although PAR yielded significant results during certain time periods, no consistent relationship with acetaldehyde exchange was found. These findings are in contrast to our hypothesis and an important difference to other VOCs (e.g., terpenoids), which often exhibit a distinct temperatureor light-driven emission pattern that is widely used in modeling approaches (Guenther et al., 1995, 2006, 2012).

Soil parameters seemingly influenced observed emission patterns to a larger degree than most other ancillary data (Table 1). The significant influence of SWC on emission fluxes can be explained by increasingly anoxic conditions near the plant roots and as a consequence thereof increased production of ethanol, an important precursor of acetaldehyde (Kreuzwieser et al., 2004). However, the significant positive correlation of SWC with acetaldehyde fluxes in both the simple and multiple linear regression when all data are pooled seemed to contradict results by Asensio et al. (2007), who reported increasing soil uptake of acetaldehyde at higher soil moistures (Table 1).

While it is difficult to find a general explanation for acetaldehyde deposition processes at ecosystem scale, a look at specific, shorter time periods reveals possible driving forces 
and the seemingly important role of SWC for acetaldehyde transport to the meadow. For example, after the meadow became snow-free on 29 March 2009, environmental conditions changed rapidly over the next 2 weeks. $T_{\text {soil }}, T_{\text {air }}, \mathrm{H}, \mathrm{LE}$ and SHF all increased significantly, but acetaldehyde fluxes were still close to zero. This changed on 15 April when the meadow started to incorporate acetaldehyde, the same time when $\mathrm{CO}_{2}$ uptake started and many parameters further increased, most notably $T_{\text {soil }}, T_{\text {air }}$ and LE, while SWC and VMR decreased. Then, during the period of the highest uptake between 12 May and 2 June (Fig. 3), SWC was extremely low and reached values that were among the lowest over all 4 years (Fig. 1), while VMR, $T_{\text {soil }}$ and $T_{\text {air }}$ continued to rise and $\mathrm{CO}_{2}$ uptake remained the same. During the same period, the correlation between VMR and flux was high $\left(r^{2}=0.48\right)$. Of these observations in the time period after snowmelt - first cut 2009 can partially be explained by earlier studies. The lack of acetaldehyde emissions during this period could be a direct consequence of missing or very low ethanol production as a consequence of low SWC (Kreuzwieser et al., 1999, 2004). Therefore, although the activity of the transpiration stream in the plants is high as indicated by high LE, only very little ethanol is transported to the leaves and acetaldehyde production by ethanol oxidation is low (Kreuzwieser et al., 2001). Acetaldehyde emission associated with this mechanism was described as a leak between acetaldehyde production and metabolism (Kreuzwieser et al., 2001). At our study site in Neustift it seems like plants are trying to avoid this leak during the strongest growing period of the year, the weeks after snowmelt right before the first cut, and to incorporate as much carbon as possible to support their growth. Fittingly, the uptake of acetaldehyde on 15 April 2009 started about 1 week after the meadow started to emit methanol at the same site (Hörtnagl et al., 2011), a compound that is known to be released as a by-product during cell wall expansion (Fall and Benson, 1996; Galbally and Kirstine, 2002). The high correlation between acetaldehyde mixing ratios and uptake could be a consequence of acetaldehyde emitted from nearby sites being transported to the meadow where it is rapidly incorporated. However, in the present study it is not possible to identify acetaldehyde sources outside the investigated flux footprint.

Observations from the period in 2009 described above can also be confirmed on a broader time scale. An ANOVA identified higher acetaldehyde VMRs on days with high deposition fluxes (average acetaldehyde flux $<-0.08 \mathrm{nmol} \mathrm{m}^{-2} \mathrm{~s}^{-1}$ ) as a significant difference to zeroflux days. In comparison to high-emission days (average flux $>0.08 \mathrm{nmol} \mathrm{m}^{-2} \mathrm{~s}^{-1}$ ), days with strong acetaldehyde uptake were characterized by significantly higher $\mathrm{CO}_{2}$ uptake, lower SWC and lower sensible heat flux. These results indicate that the quantification of additional soil parameters accompanied by concurrent ethanol measurements might be indispensable for deciphering the reasons behind acetaldehyde exchange patterns at ecosystem scale.
The positive correlation of VMRs with acetaldehyde emissions on uptake days (group $f+$, Table 1) might be misleading, as emissions of acetaldehyde from the meadow also cause ambient VMRs to rise. This observation for acetaldehyde is similar to an earlier study at the same site, where a highly positive PC between methanol VMRs and fluxes, pooled over $2 \mathrm{yr}$, was reported (Hörtnagl et al., 2011). However, no such relationship could be seen for acetaldehyde when all $4 \mathrm{yr}$ of data were pooled, which resulted in a closeto-zero PC between the 2 parameters as a direct result of their bidirectional relationship on uptake or emission days in combination with the non-existent influence of VMRs on acetaldehyde exchange on days with very low or zero fluxes (Table 1). The negative correlation of acetaldehyde VMRs on days with net uptake (group $f-$, Table 1 ) is more in line with studies reporting an acetaldehyde compensation point (e.g., Kesselmeier, 2001) and discussed below (see Sect. 4.2).

The amount of carbon emitted from the meadow as a result of the net acetaldehyde exchange in 2009, 2011 and 2012 corresponded to $2.5-4.2 \%$ of the carbon emitted due to methanol emissions during the same time period, while the respective value was considerably higher in 2008 (11.2\%). One reason for the latter could be the late start of the measurement campaign, where the period between snowmelt and the first cut - a period of high uptake rates in all other years was only partially captured (Figs. 3 and 5, see also Sect. 3.2).

A comparison of eddy covariance acetaldehyde fluxes during undisturbed conditions with other studies at ecosystem scale is difficult, as earlier publications over agricultural grassland sites mainly focused on the effect of cutting or other compounds like methanol over shorter time scales (Brunner et al., 2007; Davison et al., 2008; Karl et al., 2001a, b, c; Olofsson et al., 2003). Warneke et al. (2002) reported close-to-zero fluxes right before the cutting of an alfalfa field in August, while Graus et al. (2013, see addendum) reported average leaf level fluxes of $0.07 \mathrm{nmol} \mathrm{m}^{-2} \mathrm{~s}^{-1}$ for switch grass over a 7-day period in September, both of which are somewhat similar to average fluxes of $0.01 \mathrm{nmol} \mathrm{m}^{-2} \mathrm{~s}^{-1}$ during August and September in this study. Also in September, Custer and Schade (2007) found a median flux of $-0.01 \mathrm{nmol} \mathrm{m}^{-2} \mathrm{~s}^{-1}$ (interquartile range: -0.03 to 0.02 ) over 19 days above ryegrass. These numbers closely resemble results from Neustift, where we observed a median flux of $-0.02 \mathrm{nmol} \mathrm{m}^{-2} \mathrm{~s}^{-1}$ (-0.09 to 0.06$)$ in September.

Maximum acetaldehyde fluxes in Neustift were considerably higher than exchange rates reported from various forest ecosystems, where previous studies reported high fluxes of 0.2-1.2 $\mathrm{mg} \mathrm{m}^{-2} \mathrm{~h}^{-1}$ (Karl et al., 2002, 2003; Rinne et al., 2007), while maximum flux rates in Neustift were $1.5 \mathrm{mg}$ $\mathrm{m}^{-2} \mathrm{~h}^{-1}$ during undisturbed conditions and $2.6 \mathrm{mg} \mathrm{m}^{-2} \mathrm{~h}^{-1}$ during cutting. However, the maximum average emission from diurnal cycles (Fig. 5) was only $0.04 \mathrm{mg} \mathrm{m}^{-2} \mathrm{~h}^{-1}$, which is much lower than the 0.6 and $0.2 \mathrm{mg} \mathrm{m}^{-2} \mathrm{~h}^{-1}$ reported by Schade and Goldstein (2001) and Kaser et al. (2013), respectively, above a ponderosa pine plantation 
and lower than the $0.1 \mathrm{mg} \mathrm{m}^{-2} \mathrm{~h}^{-1}$ over a tropical rain forest (Karl et al., 2004).

Results from measurements including harvesting and drying of harvested plant material compare well to other studies. Davison et al. (2008) reported maximum acetaldehyde emissions of $19.4 \mathrm{nmol} \mathrm{m}^{-2} \mathrm{~s}^{-1}$ on the day of cutting and a daytime (7 a.m. -5 p.m.) average of $5.1 \mathrm{nmol} \mathrm{m}^{-2} \mathrm{~s}^{-1}$ over a 3-day drying phase in June for a meadow similar to Neustift near Oensingen, Switzerland. While maximum fluxes during the first cut were similar $\left(5.3-14.7 \mathrm{nmol} \mathrm{m}^{-2} \mathrm{~s}^{-1}\right)$, daytime averages were generally lower $\left(0.6-1.6 \mathrm{nmol} \mathrm{m}^{-2} \mathrm{~s}^{-1}\right)$. Similarly, Davison et al. (2008) described average daytime fluxes of $8.4 \mathrm{nmol} \mathrm{m}^{-2} \mathrm{~s}^{-1}$ on the day of cutting, much higher than in Neustift $\left(0.3-2.5 \mathrm{nmol} \mathrm{m}^{-2} \mathrm{~s}^{-1}\right)$. In Oensingen, average daytime emissions decreased by $53 \% 1$ day after the cut, and with the exception of the first cutting in 2012, when emissions increased by 1 order of magnitude, we observed the same decrease in Neustift (54\% on average). Average daytime VMRs in Neustift also compared well, decreasing from $0.81 \mathrm{ppbv}$ on the day of cutting to $0.48 \mathrm{ppbv} 3$ days later (Oensingen: from 1.84 to $0.29 \mathrm{ppbv}$ ).

Davison et al. (2008) reported emission peaks of about $10 \mathrm{nmol} \mathrm{m}^{-2} \mathrm{~s}^{-1}$ due to the turning of the hay to support the drying process, about half as large as maximum emissions during the cutting. These peaks were also found in Neustift, however, emission fluxes during the first cut in June were often much higher when the hay was turned or shortly after all grass was removed from the field than during harvesting (Fig. 4, see also Sect. 3.3). The abrupt decline of acetaldehyde emissions after the removal of the hay as seen by Davison et al. (2008) was less distinct in Neustift, especially during the third cut in September, when the influence could be seen for up to 5 days after the event (Fig. 4).

Our findings are very similar to Karl et al. (2001b), who reported high fluxes of acetaldehyde between 0.5$3 \mathrm{mg} \mathrm{m}^{-2} \mathrm{~h}^{-1}$ after the cutting of a hayfield in August, nearly the same as those recorded in Neustift $\left(0.7-2.6 \mathrm{mg} \mathrm{m}^{-2} \mathrm{~h}^{-1}\right)$. Warneke et al. (2002) described daily integrated acetaldehyde emissions of $8.9 \mathrm{mg} \mathrm{m}^{-2}$ from $0.40 \mathrm{~kg}$ plant matter (PM) after the cutting of an alfalfa field in August and the drying on the field over the following 2 days, which was much lower than $15.9-20.2 \mathrm{mg} \mathrm{m}^{-2}$ during the second cut in Neustift, but similar to values observed during the first and third cut (4.5-9.6 $\mathrm{mg} \mathrm{m}^{-2}$ ). In contrast to the alfalfa field the grass in Neustift was normally collected on the day of cutting or 1 day later, and some of the emission spikes were caused by the hay turning. However, the cut grass was left on the meadow for 2 days in September 2009, when we recorded $5.3 \mathrm{mg} \mathrm{m}^{-2}$ from $0.43 \mathrm{~kg} \mathrm{PM} \mathrm{m}^{-2}$.

At ecosystem scale, a comparison of acetaldehyde emissions in $\mu \mathrm{g}$ per gram dry weight $\left(\mu \mathrm{gdw}^{-1}\right)$ might provide important information not only when upscaling local fluxes to a global scale based on plant functional groups, but also when comparing eddy covariance fluxes to laboratory experiments. Brilli et al. (2012) showed that leaf or plant enclosure measurements of BVOCs under laboratory conditions can yield similar results in comparison to ecosystem flux measurements scaled to the amount of harvested plant material. Several studies have reported acetaldehyde emissions from cut and drying plants (Warneke et al., 2002), for example $40 \mathrm{gg} \mathrm{gdw}^{-1}$ for cut grass from an enclosure measurement (Kirstine et al., 1998), 20-80 $\mu \mathrm{gdw}^{-1}$ for drying grass in an laboratory experiment (Karl et al., 2001b), 3-80 $\mu \mathrm{g} \mathrm{gdw}^{-1}$ for cut clover (Trifolium repens; Brilli et al., 2012; De Gouw et al., 2000; Kirstine et al., 1998) and between 6-9 $\mathrm{gg} \mathrm{gdw}^{-1}$ for the day of harvesting and 2 drying days (Warneke et al., 2002). Brilli et al. (2012) also give numbers for Dactylis glomerata ( $1 \mu \mathrm{g}$ acetaldehyde $\mathrm{gdw}^{-1}$ over $24 \mathrm{~h}$ after cutting) and Ranunculus acris (3). In comparison, when the cut grass was left on the field in Neustift, we observed acetaldehyde emissions of $1-19 \mu \mathrm{gdw}^{-1}$ on the day of cutting and 6$33 \mu \mathrm{gdw}^{-1}$ over 2 days of drying, with maximum fluxes in August. Despite the different plant composition these numbers are similar to the findings of Warneke et al. (2002), who reported $6 \mu \mathrm{gdw}^{-1}$ on the cut day and $15 \mu \mathrm{gdw}^{-1}$ cumulative during cutting and drying. The same study described acetaldehyde VMRs of around 2 ppbv directly before and up to 8 ppbv during the cutting, much higher than in Neustift (around 0.5 and 2.5-4.5 ppbv, respectively).

Acetaldehyde fluxes described by Warneke et al. (2002) were generally very similar to the present study: after closeto-zero fluxes right before the cutting, acetaldehyde emissions increased rapidly and reached a maximum on the day after the harvesting, with a stronger increase during the drying phase than during the cutting itself. Similar emission bursts were observed for methanol at the same site by Hörtnagl et al. (2011), and in the case of acetaldehyde the reason for these massive emissions may be similar, when acetaldehyde in the liquid phase inside the damaged plant cells is suddenly exposed to the atmosphere as a consequence of the wounding. The question if these pools are always present or if acetaldehyde is formed directly as a consequence of the harvesting, for example from pyruvate by an unknown mechanism upon wounding (Loreto et al., 2006), merits further study. Loreto et al. (2006) reported acetaldehyde emissions remote from the wounding site for Phragmites leaves on leaf level scale, where emissions from ethanol transported to the leaves seemed unlikely, as no ethanol emissions were associated with the acetaldehyde burst. Remotely triggered emissions due to mechanical stress could also play a role in Neustift, for example after the first cut in 2011 when maximum emissions were observed directly after all grass had been removed from the field and all liquid phase acetaldehyde at the wounding site may already have escaped to the atmosphere (Fig. 4, see also Sect. 3.3).

Loreto et al. (2006) further described the absence of acetaldehyde emissions from Phragmites leaves when the leaves were immediately placed in water instead of leaving them in air, and further reported the possibility of a strong stomatal control on acetaldehyde emissions because 
of wounding or high light exposure as well as a delayed response to high temperatures. These observations on leaf level could be one explanation for the low acetaldehyde emissions on the day of the first cut in 2012, followed by massive emissions of acetaldehyde on the following 2 days. On the day of cutting, a light rain contributed to the already wet conditions in the canopy by falling on the cut grass that was still on the field, possibly preventing the majority of acetaldehyde that was solved in the liquid phase from escaping from the wounding site to the atmosphere by keeping them adsorbed on or within the cut grass. On the next day when weather conditions were sunny and dry, emissions increased sharply before the majority of adsorbed acetaldehyde was released in two massive bursts during the turning and collection of the hay (Fig. 4). This observation could be similar to earlier studies, where increased acetaldehyde emissions from drying alfalfa after rainfall (Warneke et al., 2002) and from wetted plant material in the laboratory (Warneke et al., 1999) were reported. After all grass was removed from the field, fluxes suddenly dropped to zero, indicating that all previous emissions after the cut were due to the harvesting itself, the temperature-driven drying process or the grass turning. One day after all grass was removed emissions began to rise tenfold as soon as sunlight reached the vegetation in the morning while also surface conductance was high (data not shown). Up to this point only little light had reached the short vegetation below the overlying grass cover for nearly $24 \mathrm{~h}$ and light conditions for the lower canopy were already relatively dark before the harvesting due to high GAI and low PAR. If the observation of a possible strong stomatal control on acetaldehyde emissions because of wounding or high light exposure described by Loreto et al. (2006) was to be examined at ecosystem scale, the conditions during this morning would be a good comparison to respective laboratory experiments. This pattern of high emissions after all grass was removed from the field was observed several times (e.g., first cut 2011, see also Sect. 3.3).

Regarding anthropogenic management actions the spreading of liquid manure on the field may constitute another, minor source of acetaldehyde. Earlier studies described the strong impact of fertilization on biological and biochemical processes (Ros et al., 2006). For example, Seewald et al. (2010) reported elevated acetaldehyde emissions from soil samples and a change of microbial community composition after the application of mineral fertilizer in combination with sewage sludge compost. Therefore, increased acetaldehyde emissions during and some days after manure spreading in 2009 and to a lesser extent in 2011 could be a direct effect of increased microbial activity in the soil. The emission spike on 19 October 2011 at 7 a.m. followed by high deposition fluxes $30 \mathrm{~min}$ later could be a combination of multiple factors: first, acetaldehyde production in the soil increased during the first part of fertilization on 18 October, but emissions remained low and fluctuated around zero, possibly held back or dampened by starting dew formation later in the evening. Then, 1 day later, built-up acetaldehyde was released instantly in the morning, the same time when the nightly frost-cover on the meadow thawed and adsorbed acetaldehyde was revolatized (Seco et al., 2007). This resulted in a huge emission spike (Fig. 4) and high ambient VMRs. Now, with acetaldehyde VMRs in the soil being low, a deposition process started according to Fick's first law of diffusion and acetaldehyde was transported to the meadow, resulting in a net uptake of the compound. However, the exact origin of acetaldehyde fluxes cannot be determined with the eddy covariance method, simultaneous soil measurements of acetaldehyde would definitely expand the room for interpretation of observed exchange patterns.

\subsection{Compensation point}

Over the course of a year the relationship between acetaldehyde VMRs and fluxes changed constantly. This complex interaction was reflected by varying values for $C^{*}$ throughout the year, which is in accordance with our hypothesis. From a very general perspective, our results confirm findings by Karl et al. (2005) who found varying compensation points of loblolly pine needles, with $C^{*}$ between 3.7 and $8.5 \mathrm{ppb}$, which is by more than 1 order of magnitude higher than values found for the grassland at Neustift (Fig. 7, see Sect. 3.6) but similar to other tree studies (Cojocariu et al., 2004). Although we did not find $C^{*}$ exponentially increasing like described by Karl et al. (2005), we identified $T_{\text {air }}$ and $T_{\text {soil }}$ as significant parameters (Table 2).

The main difference of the present study to other $C^{*}$ investigations is the existence of both a positive and a negative relationship between mixing ratios and fluxes, reflecting the complex relationship at ecosystem scale (Fig. 7). Table 2 shows that NEE plays a highly significant role in group N2, meaning a low compensation point in times of high $\mathrm{CO}_{2}$ uptake, which would facilitate the deposition of acetaldehyde into the plant and fits flux observations in this study. In the same group increasing $T_{\text {soil }}$ lead to decreasing $C^{*}$ values, which could in part be a consequence of microbial processes in the soil that facilitate acetaldehyde uptake. Due to a high goodness of fit between acetaldehyde VMR and flux, groups $\mathrm{N} 1$ and $\mathrm{P} 1$ yielded the most reliable results and will be discussed in the following.

Some of our observations are in line with findings by Jardine et al. (2008), who described $C^{*}$ as a function of light, temperature and ambient acetaldehyde concentrations at leaf level. However, it seems that at ecosystem scale different parameters influence $C^{*}$ during different time periods, strongly depending on whether the correlation between VMR and flux is positive or negative (Table 2). The high correlation between VMR and $C^{*}$ in N1 seems to reflect Fick's first law of diffusion. During periods when both $C^{*}$ and ambient VMRs are low and mixing ratios start to rise, acetaldehyde starts to diffuse into the plants, i.e., the leaf-internal acetaldehyde levels increase. This in turn causes the gradient between internal 
and ambient acetaldehyde VMRs to decrease, slowing or stopping the diffusion process. For the gradient to build up again, it needs either less internally stored acetaldehyde or higher ambient VMRs. As shown before, the meadow in Neustift only emits minor amounts of acetaldehyde during undisturbed conditions (Fig. 3), therefore an increase of ambient acetaldehyde mixing ratios might be a more likely scenario. At this point, with VMRs further increasing, plants have already taken up considerable amounts of acetaldehyde and leaf-internal acetaldehyde levels are relatively high, reflected by a high $C^{*}$. Therefore, high compensation points at ecosystem scale at the study site in Neustift might be the consequence of preceding periods of acetaldehyde uptake in combination with little or no emission fluxes, which would mean that an increase of $C^{*}$ at our meadow could be controlled by external factors as opposed to leaf-internal processes (Jardine et al., 2008).

During periods of low ambient VMRs and low $C^{*}$ the canopy might further be more susceptible to uptake of acetaldehyde that was transported to the meadow from external sites. It might be of note that during the strong uptake period before the first cut 2009 analyzed in 4.1, $C^{*}$ remains about the same (Fig. 7), indicating that leaf-internal acetaldehyde might be consumed by an unknown process. Table 2 further shows that low SHF resulted in lower $C^{*}$, meaning that uptake of acetaldehyde is facilitated. This seems to confirm our findings in Table 1, where decreasing SHF was positively correlated with acetaldehyde uptake on deposition days.

The negative slope between acetaldehyde mixing ratios and fluxes calculated in Fig. 7 is influenced significantly by multiple parameters in N1 (Table 2), most notably VPD and PAR, whereby the former is positively, and the latter is negatively correlated with slope $k$. During periods of high VPD there may be more LE with plants drawing more water through their roots, which could result in increased ethanol oxidation in the leaves and higher leaf-internal acetaldehyde. This in turn would increase $C^{*}$, resulting in a slower deposition of ambient acetaldehyde to the canopy. Similarly, high PAR is often associated with high $T_{\text {air }}$, both of which can increase acetaldehyde emission (Loreto et al., 2006). In such case, increased acetaldehyde production in the plant would lead to an increased $C^{*}$ and in less uptake of ambient acetaldehyde. This internal production might also be fueled by high SWC (more ethanol production) and high LE (more transport of ethanol to the leaves), both of which decreased the steepness of slope $k$ in N1 (Table 2).

Discussing the positive correlation between acetaldehyde mixing ratios and respective fluxes is challenging (Table 1, Figs. 6, 8), as it seems plausible that high ambient VMRs are found during and as a result of periods of high acetaldehyde emission at or near the study site. Also, environmental parameters were not able to explain slope $k$ in groups $\mathrm{P} 1$ and P2 satisfyingly (Table 2), which is an apparent contrast to groups N1 and N2 and indicates that there might be other factors involved than environmental drivers available in this study.

\section{Summary}

Our analysis of acetaldehyde fluxes measured over four growing seasons between 2008-2012 show that in contrast to other VOCs, air temperature and photosynthetic active radiation do not explain observed acetaldehyde exchange patterns at the investigated grassland ecosystem.

The cutting of the meadow resulted in massive bursts of acetaldehyde, either released on the day of harvesting, during drying when the grass was left on the field or immediately after all grass was removed from the meadow. Emission values from this study compared well to laboratory or in situ measurements investigating cutting-related acetaldehyde emissions. Due to management events, the meadow acted as a source of acetaldehyde in all 4 years, while it was a net sink of acetaldehyde in 3 of 4 years with management actions excluded.

In comparison to days with high acetaldehyde emission, high-deposition days during undisturbed conditions were characterized by higher $\mathrm{CO}_{2}$ uptake rates in combination with lower soil water content and lower sensible heat flux, while acetaldehyde VMRs were similar and higher than on zero-flux days.

The calculation of acetaldehyde compensation points revealed a complex relationship between ambient acetaldehyde mixing ratios and respective fluxes that changed constantly throughout the year. While the correlation between these 2 parameters was negative during certain time periods as expected, it was positive during others. It was further shown that slope $k$ associated with negative correlations is influenced by multiple environmental parameters, each of which increases or slows down deposition from the atmosphere to the canopy. In order to model acetaldehyde fluxes at the site in Neustift it is important to know the relationship between mixing ratios and fluxes on a given day.

Eddy covariance measurements of acetaldehyde at ecosystem scale would benefit greatly when performed in combination with simultaneous soil measurements quantifying VOC exchange, measurements within the canopy to learn more about (VOC) gradients and laboratory experiments targeting ethanol production in plants.

The Supplement related to this article is available online at doi:10.5194/acp-14-5369-2014-supplement. 
Acknowledgements. This study was financially supported by the Austrian National Science Fund under contracts P19849-B16 and P23267-B16, by the Tyrolean Science Fund under contracts Uni-404/486 and Uni-404/1083. Family Hofer (Neustift, Austria) is acknowledged for granting us access to the study site. Additional support was obtained by the Translational-Research-Programm (L518-N20) of the Austrian National Science Fund and the Industry-Academia Partnerships and Pathways (IAPP; 218065) funded by the European Commission.

Edited by: L. Ganzeveld

\section{References}

Asensio, D., Peñuelas, J., Filella, I., and Llusià, J.: On-line screening of soil VOCs exchange responses to moisture, temperature and root presence, Plant. Soil, 291, 249-261, doi:10.1007/s11104-006-9190-4, 2007.

Atkinson, R.: Atmospheric chemistry of VOCs and $\mathrm{NO}_{\mathrm{x}}$, Atmos. Environ., 34, 2063-2101, doi:10.1016/S1352-2310(99)00460-4, 2000.

Atkinson, R., Baulch, D. L., Cox, R. A., Crowley, J. N., Hampson, R. F., Hynes, R. G., Jenkin, M. E., Rossi, M. J., and Troe, J.: Evaluated kinetic and photochemical data for atmospheric chemistry: Volume II - gas phase reactions of organic species, Atmos. Chem. Phys., 6, 3625-4055, doi:10.5194/acp-6-3625-2006, 2006.

Aubinet, M., Grelle, A., Ibrom, A., Rannik, Ü., Moncrieff, J., Foken, T., Kowalski, A. S., Martin, P. H., Berbigier, P., Bernhofer, C., Clement, R., Elbers, J., Granier, A., Grünwald, T., Morgenstern, K., Pilegaard, K., Rebmann, C., Snijders, W., Valentini, R., and Vesala, T.: Estimates of the Annual Net Carbon and Water Exchange of Forests: The EUROFLUX Methodology, Adv. Ecol. Res., 30, 113-175, doi:10.1016/S0065-2504(08)60018-5, 2000.

Baldocchi, D. D., Hincks, B. B., and Meyers, T. P.: Measuring Biosphere-Atmosphere Exchanges of Biologically Related Gases with Micrometeorological Methods, Ecology, 69, 13311340, doi:10.2307/1941631, 1988.

Bamberger, I., Hörtnagl, L., Schnitzhofer, R., Graus, M., Ruuskanen, T. M., Müller, M., Dunkl, J., Wohlfahrt, G., and Hansel, A.: BVOC fluxes above mountain grassland, Biogeosciences, 7, 1413-1424, doi:10.5194/bg-7-1413-2010, 2010.

Bamberger, I., Hörtnagl, L., Ruuskanen, T. M., Schnitzhofer, R., Müller, M., Graus, M., Karl, T., Wohlfahrt, G., and Hansel, A.: Deposition fluxes of terpenes over grassland, J. Geophys. Res., 116, D14305, doi:10.1029/2010JD015457, 2011.

Brilli, F., Ruuskanen, T. M., Schnitzhofer, R., Müller, M., Breitenlechner, M., Bittner, V., Wohlfahrt, G., Loreto, F., and Hansel, A.: Detection of plant volatiles after leaf wounding and darkening by proton transfer reaction "time-offlight" mass spectrometry (PTR-TOF), PLoS One, 6, e20419, doi:10.1371/journal.pone.0020419, 2011.

Brilli, F., Hörtnagl, L., Bamberger, I., Schnitzhofer, R., Ruuskanen, T. M., Hansel, A., Loreto, F., and Wohlfahrt, G.: Qualitative and quantitative characterization of volatile organic compound emissions from cut grass, Environ. Sci. Technol., 46, 3859-3865, doi:10.1021/es204025y, 2012.
Brunner, A., Ammann, C., Neftel, A., and Spirig, C.: Methanol exchange between grassland and the atmosphere, Biogeosciences, 4, 395-410, doi:10.5194/bg-4-395-2007, 2007.

Cojocariu, C., Kreuzwieser, J., and Rennenberg, H.: Correlation of short-chained carbonyls emitted from Picea abies with physiological and environmental parameters, New Phytologist, 162, 717-727, doi:10.1111/j.1469-8137.2004.01061.x, 2004.

Cojocariu, C., Escher, P., Haberle, K.-H., Matyssek, R., Rennenberg, H., and Kreuzwieser, J.: The effect of ozone on the emission of carbonyls from leaves of adult Fagus sylvatica, Plant. Cell Environ., 28, 603-611, doi:10.1111/j.1365-3040.2005.01305.x, 2005.

Custer, T. and Schade, G.: Methanol and acetaldehyde fluxes over ryegrass, Tellus B, 59, 673-684, doi:10.1111/j.16000889.2007.00294.x, 2007.

Davison, B., Brunner, A., Ammann, C., Spirig, C., Jocher, M., and Neftel, A.: Cut-induced VOC emissions from agricultural grasslands, Plant Biol. (Stuttgart, Germany), 10, 76-85, doi:10.1055/s-2007-965043, 2008.

De Gouw, J. A., Howard, C. J., Custer, T. G., Baker, B., and Fall, R.: Proton-Transfer Chemical-Ionization Mass Spectrometry Allows Real-Time Analysis of Volatile Organic Compounds Released from Cutting and Drying of Crops, Environ. Sci. Technol., 34, 2640-2648, doi:10.1021/es991219k, 2000.

Fall, R.: Abundant oxygenates in the atmosphere: a biochemical perspective, Chem. Rev., 103,, 4941-4952, doi:10.1021/cr0206521, 2003.

Fall, R. and Benson, A. A.: Leaf methanol - the simplest natural product from plants, Trend. Plant Sci., 1, 296-301, doi:10.1016/S1360-1385(96)88175-0, 1996.

Filella, I., Wilkinson, M. J., Llusià, J., Hewitt, C. N., and Peñuelas, J.: Volatile organic compounds emissions in Norway spruce (Picea abies) in response to temperature changes, Physiol. Plantarum, 130, 58-66, doi:10.1111/j.1399-3054.2007.00881.x, 2007.

Foken, T. and Wichura, B.: Tools for quality assessment of surfacebased flux measurements, Agr. Forest Meteorol., 78, 83-105, doi:10.1016/0168-1923(95)02248-1, 1996.

Galbally, I. I. E. and Kirstine, W.: The Production of Methanol by Flowering Plants and the Global Cycle of Methanol, J. Atmos. Chem., 43, 195-229, doi:10.1023/A:1020684815474, 2002.

Goldstein, A. H. and Galbally, I. E.: Known and Unexplored Organic Constituents in the Earth's Atmosphere, Environ. Sci. Technol., 41, 1514-1521, doi:10.1021/es072476p, 2007.

Graus, M., Eller, A. S. D., Fall, R., Yuan, B., Qian, Y., Westra, P., de Gouw, J., and Warneke, C.: Biosphere-atmosphere exchange of volatile organic compounds over $\mathrm{C} 4$ biofuel crops, Atmos. Environ., 66, 161-168, doi:10.1016/j.atmosenv.2011.12.042, 2013.

Greenberg, J. P., Asensio, D., Turnipseed, A., Guenther, A. B., Karl, T., and Gochis, D.: Contribution of leaf and needle litter to whole ecosystem BVOC fluxes, Atmos. Environ., 59, 302-311, doi:10.1016/j.atmosenv.2012.04.038, 2012.

Guenther, A., Hewitt, C. N., Erickson, D., Fall, R., Geron, C., Graedel, T., Harley, P., Klinger, L., Lerdau, M., Mckay, W. A., Pierce, T., Scholes, B., Steinbrecher, R., Tallamraju, R., Taylor, J., and Zimmerman, P.: A global model of natural volatile organic compound emissions, J. Geophys. Res., 100, 8873-8892, doi:10.1029/94JD02950, 1995. 
Guenther, A., Karl, T., Harley, P., Wiedinmyer, C., Palmer, P. I., and Geron, C.: Estimates of global terrestrial isoprene emissions using MEGAN (Model of Emissions of Gases and Aerosols from Nature), Atmos. Chem. Phys., 6, 3181-3210, doi:10.5194/acp-63181-2006, 2006.

Guenther, A. B., Jiang, X., Heald, C. L., Sakulyanontvittaya, T., Duhl, T., Emmons, L. K., and Wang, X.: The Model of Emissions of Gases and Aerosols from Nature version 2.1 (MEGAN2.1): an extended and updated framework for modeling biogenic emissions, Geosci. Model Dev., 5, 1471-1492, doi:10.5194/gmd-51471-2012, 2012.

Hammerle, A., Haslwanter, A., Tappeiner, U., Cernusca, A., and Wohlfahrt, G.: Leaf area controls on energy partitioning of a temperate mountain grassland, Biogeosciences, 5, 421-431, doi:10.5194/bg-5-421-2008, 2008.

Hansel, A., Jordan, A., Holzinger, R., Prazeller, P., Vogel, W., and Lindinger, W.: Proton transfer reaction mass spectrometry: online trace gas analysis at the ppb level, Int. J. Mass Spectrom. Ion Process., 149-150, 609-619, doi:10.1016/0168-1176(95)04294U, 1995.

Hayward, S., Tani, A., Owen, S. M., and Hewitt, C. N.: Online analysis of volatile organic compound emissions from Sitka spruce (Picea sitchensis), Tree Physiol., 24, 721-728, doi:10.1093/treephys/24.7.721, 2004.

Hörtnagl, L., Clement, R., Graus, M., Hammerle, A., Hansel, A., and Wohlfahrt, G.: Dealing with disjunct concentration measurements in eddy covariance applications: A comparison of available approaches, Atmos. Environ., 44, 2024-2032, doi:10.1016/j.atmosenv.2010.02.042, 2010.

Hörtnagl, L., Bamberger, I., Graus, M., Ruuskanen, T. M., Schnitzhofer, R., Müller, M., Hansel, A., and Wohlfahrt, G.: Biotic, abiotic, and management controls on methanol exchange above a temperate mountain grassland, J. Geophys. Res., 116, 1-15, doi:10.1029/2011JG001641, 2011.

Hsieh, C.-I., Katul, G., and Chi, T.: An approximate analytical model for footprint estimation of scalar fluxes in thermally stratified atmospheric flows, Adv. Water Resour., 23, 765-772, doi:10.1016/S0309-1708(99)00042-1, 2000.

Jardine, K., Harley, P., Karl, T., Guenther, A., Lerdau, M., and Mak, J. E.: Plant physiological and environmental controls over the exchange of acetaldehyde between forest canopies and the atmosphere, Biogeosciences, 5, 1559-1572, doi:10.5194/bg-5-15592008, 2008.

Jardine, K., Barron-Gafford, G. A., Norman, J. P., Abrell, L., Monson, R. K., Meyers, K. T., Pavao-Zuckerman, M., Dontsova, K., Kleist, E., Werner, C., and Huxman, T. E.: Green leaf volatiles and oxygenated metabolite emission bursts from mesquite branches following light-dark transitions, Photosynt. Res., 113, 321-333, doi:10.1007/s11120-012-9746-5, 2012.

Karl, T., Fall, R., Jordan, A., and Lindinger, W.: On-line analysis of reactive VOCs from urban lawn mowing, Environ. Sci. Technol., 35, 2926-2931, 2001a.

Karl, T., Guenther, A., Jordan, A., Fall, R., and Lindinger, W.: Eddy covariance measurement of biogenic oxygenated VOC emissions from hay harvesting, Atmos. Environ., 35, 491-495, doi:10.1016/S1352-2310(00)00405-2, 2001b.
Karl, T., Guenther, A., Lindinger, C., Jordan, A., Fall, R., and Lindinger, W.: Eddy covariance measurements of oxygenated volatile organic compound fluxes from crop harvesting using a redesigned proton-transfer-reaction mass spectrometer, J. Geophys. Res., 106, 24157-24167, 2001c.

Karl, T., Curtis, A. J., Rosenstiel, T. N., Monson, R. K., and Fall, R.: Transient releases of acetaldehyde from tree leaves-products of a pyruvate overflow mechanism? Plant. Cell Environ., 25, 11211131, 2002a.

Karl, T. G., Spirig, C., Rinne, J., Stroud, C., Prevost, P., Greenberg, J., Fall, R., and Guenther, A.: Virtual disjunct eddy covariance measurements of organic compound fluxes from a subalpine forest using proton transfer reaction mass spectrometry, Atmos. Chem. Phys., 2, 279-291, doi:10.5194/acp-2-279-2002, 2002 b.

Karl, T., Guenther, A., Spirig, C., Hansel, A., and Fall, R.: Seasonal variation of biogenic VOC emissions above a mixed hardwood forest in northern Michigan, Geophys. Res. Lett., 30, 2186, doi:10.1029/2003GL018432, 2003.

Karl, T., Potosnak, M., Guenther, A., Clark, D., Walker, J., Herrick, J. D., and Geron, C.: Exchange processes of volatile organic compounds above a tropical rain forest: Implications for modeling tropospheric chemistry above dense vegetation, J. Geophys. Res., 109, D18306, doi:10.1029/2004JD004738, 2004.

Karl, T., Harley, P., Guenther, A., Rasmussen, R., Baker, B., Jardine, K., and Nemitz, E.: The bi-directional exchange of oxygenated VOCs between a loblolly pine (Pinus taeda) plantation and the atmosphere, Atmos. Chem. Phys., 5, 3015-3031, doi:10.5194/acp5-3015-2005, 2005.

Karl, T., Harley, P., Emmons, L., Thornton, B., Guenther, a, Basu, C., Turnipseed, A., and Jardine, K.: Efficient atmospheric cleansing of oxidized organic trace gases by vegetation, Science (New York, N.Y.), 330, 816-819, doi:10.1126/science.1192534, 2010.

Kaser, L., Karl, T., Schnitzhofer, R., Graus, M., Herdlinger-Blatt, I. S., DiGangi, J. P., Sive, B., Turnipseed, A., Hornbrook, R. S., Zheng, W., Flocke, F. M., Guenther, A., Keutsch, F. N., Apel, E., and Hansel, A.: Comparison of different real time VOC measurement techniques in a ponderosa pine forest, Atmos. Chem. Phys., 13, 2893-2906, doi:10.5194/acp-13-2893-2013, 2013.

Kesselmeier, J.: Exchange of short-chain oxygenated volatile organic compounds (VOCs) between plants and the atmosphere: A compilation of field and laboratory studies, J. Atmos. Chem., 39, 219-233, doi:10.1023/A:1010632302076, 2001.

Kesselmeier, J. and Staudt, M.: Biogenic volatile organic compounds (VOC): an overview on emission, physiology and ecology, J. Atmos. Chem., 33, 23-88, doi:10.1023/A:1006127516791, 1999.

Kieber, R. J., Zhou, X., and Mopper, K.: Formation of carbonyl compounds from UV-induced photodegradation of humic substances in natural waters: Fate of riverine carbon in the sea, Limnol. Oceanogr., 35, 1503-1515, 1990.

Kirstine, W., Galbally, I. E., Ye, Y., and Hooper, M.: Emissions of volatile organic compounds (primarily oxygenated species) from pasture, J. Geophys. Res., 103, 10605-10619, doi:10.1029/97JD03753, 1998.

Kondo, T., Hasegawa, K., Uchida, R., and Onishi, M.: Absorption of atmospheric C2-C5 aldehydes by various tree species and their tolerance to C2-C5 aldehydes, Sci. Total Environ., 224, 121132, doi:10.1016/S0048-9697(98)00320-9, 1998. 
Kotzias, D., Konidara, C., and Spartà, C.: Volatile carbonyl compounds of biogenic origin. Emission and concentration in the atmosphere, in Biogenic Volatile Organic Compounds in the Atmosphere - Summary of Present Knowledge, edited by: Helas, G., Slanina, S., and Steinbrecher, R., 67-78, SPB Academic Publishers, Amsterdam., 1997.

Kreuzwieser, J., Scheerer, U., and Rennenberg, H.: Metabolic origin of acetaldehyde emitted by poplar (Populus tremula x P. alba) trees, J. Experiment. Bot., 50, 757-765, doi:10.1093/jxb/50.335.757, 1999.

Kreuzwieser, J., Harren, F. J. M., Laarhoven, L. J. J., Boamfa, I., te Lintel-Hekkert, S., Scheerer, U., Huglin, C., and Rennenberg, H.: Acetaldehyde emission by the leaves of trees - correlation with physiological and environmental parameters, Physio. Plantarum, 113, 41-49, doi:10.1034/j.1399-3054.2001.1130106.x, 2001.

Kreuzwieser, J., Papadopoulou, E., and Rennenberg, H.: Interaction of flooding with carbon metabolism of forest trees, Plant Biol. (Stuttgart, Germany), 6, 299-306, doi:10.1055/s-2004-817882, 2004.

Ku, F., Martis, A., Rennenberg, H., Urban, W., Kreuzwieser, J., and Kuhnemann, F.: Diurnal pattern of acetaldehyde emission by flooded poplar trees, Physio. Plantarum, 108, 79-86, doi:10.1034/j.1399-3054.2000.108001079.x, 2000.

Langford, B., Davison, B., Nemitz, E., and Hewitt, C. N.: Mixing ratios and eddy covariance flux measurements of volatile organic compounds from an urban canopy (Manchester, UK), Atmos. Chem. Phys., 9, 1971-1987, doi:10.5194/acp-9-1971-2009, 2009.

Lindinger, W., Hansel, A., and Jordan, A.: On-line monitoring of volatile organic compounds at pptv levels by means of proton-transfer-reaction mass spectrometry (PTR-MS) medical applications, food control and environmental research, Int. J. Mass Spectrom. Ion Process., 173, 191-241, doi:10.1016/S01681176(97)00281-4, 1998.

Loreto, F., Barta, C., Brilli, F., and Nogues, I.: On the induction of volatile organic compound emissions by plants as consequence of wounding or fluctuations of light and temperature., Plant. Cell Environ., 29, 1820-1828, doi:10.1111/j.13653040.2006.01561.x, 2006.

Martin, R. S., Villanueva, I., Zhang, J., and Popp, C. J.: Nonmethane Hydrocarbon, Monocarboxylic Acid, and Low Molecular Weight Aldehyde and Ketone Emissions from Vegetation in Central New Mexico, Environ. Sci. Technol., 33, 2186-2192, doi:10.1021/es980468q, 1999.

Massman, W. J.: A simple method for estimating frequency response corrections for eddy covariance systems, Agr. Forest Meteorol., 104, 247-251, doi:10.1016/S0168-1923(00)00164-7, 2000.

McMillen, R. T.: An eddy correlation technique with extended applicability to non-simple terrain, Bound.-Layer Meteorol., 43, 231-245, doi:10.1007/BF00128405, 1988.

Millet, D. B., Guenther, A., Siegel, D. A., Nelson, N. B., Singh, H. B., de Gouw, J. A., Warneke, C., Williams, J., Eerdekens, G., Sinha, V., Karl, T., Flocke, F., Apel, E., Riemer, D. D., Palmer, P. I., and Barkley, M.: Global atmospheric budget of acetaldehyde: 3-D model analysis and constraints from in-situ and satellite observations, Atmos. Chem. Phys., 10, 3405-3425, doi:10.5194/acp-10-3405-2010, 2010.
Moore, C. J.: Frequency response corrections for eddy correlation systems, Bound.-Layer Meteorol., 37, 17-35, doi:10.1007/BF00122754, 1986.

Müller, K., Haferkorn, S., Grabmer, W., Wisthaler, A., Hansel, A., Kreuzwieser, J., Cojocariu, C., Rennenberg, H., and Herrmann, H.: Biogenic carbonyl compounds within and above a coniferous forest in Germany, Atmos. Environ., 40, 81-91, doi:10.1016/j.atmosenv.2005.10.070, 2006.

Müller, M., Graus, M., Ruuskanen, T. M., Schnitzhofer, R., Bamberger, I., Kaser, L., Titzmann, T., Hörtnagl, L., Wohlfahrt, G., Karl, T., and Hansel, A.: First eddy covariance flux measurements by PTR-TOF, Atmos. Meas. Tech., 3, 387-395, doi:10.5194/amt-3-387-2010, 2010.

Olofsson, M., Ek-Olausson, B., Ljungström, E., and Langer, S.: Flux of organic compounds from grass measured by relaxed eddy accumulation technique, J. Environ. Monit., 5, 963-970, doi:10.1039/b303329e, 2003.

Possanzini, M., Palo, V. Di, and Cecinato, A.: Sources and photodecomposition of formaldehyde and acetaldehyde in Rome ambient air, Atmos. Environ., 36, 3195-3201, doi:10.1016/S13522310(02)00192-9, 2002.

Rinne, J., Taipale, R., Markkanen, T., Ruuskanen, T. M., and Hell, H.: Hydrocarbon fluxes above a Scots pine forest canopy: measurements and modeling, Atmos. Chem. Phys., 7, 3361-3372, doi:10.5194/acp-7-3361-2007, 2007.

Roberts, J.: The atmospheric chemistry of organic nitrates, Atmospheric Environment. Part A. General Topics, 24, 243-287, doi:10.1016/0960-1686(90)90108-Y, 1990.

Ros, M., Klammer, S., Knapp, B., Aichberger, K., and Insam, H.: Long-term effects of compost amendment of soil on functional and structural diversity and microbial activity, Soil Use Manage., 22, 209-218, doi:10.1111/j.1475-2743.2006.00027.x, 2006.

Rottenberger, S., Kuhn, U., Wolf, A., Schebeske, G., Oliva, S., Tavares, T., and Kesselmeier, J.: Exchange of short-chain aldehydes between Amazonian vegetation and the atmosphere, Ecol. Appl., 14, 247-262, doi:10.1890/01-6027, 2004.

Rottenberger, S., Kuhn, U., Wolf, A., Schebeske, G., Oliva, S. T., Tavares, T. M., and Kesselmeier, J.: Formaldehyde and acetaldehyde exchange during leaf development of the Amazonian deciduous tree species Hymenaea courbaril, Atmos. Environ., 39, 2275-2279, doi:10.1016/j.atmosenv.2004.12.027, 2005.

Rottenberger, S., Kleiss, B., Kuhn, U., Wolf, A., Piedade, M. T. F., Junk, W., and Kesselmeier, J.: The effect of flooding on the exchange of the volatile $\mathrm{C}_{2}$-compounds ethanol, acetaldehyde and acetic acid between leaves of Amazonian floodplain tree species and the atmosphere, Biogeosciences, 5, 1085-1100, doi:10.5194/bg-5-1085-2008, 2008.

Rumsey, I. C., Aneja, V. P., and Lonneman, W. A.: Characterizing non-methane volatile organic compounds emissions from a swine concentrated animal feeding operation, Atmos. Environ., 47, 348-357, doi:10.1016/j.atmosenv.2011.10.055, 2012.

Ruuskanen, T. M., Müller, M., Schnitzhofer, R., Karl, T., Graus, M., Bamberger, I., Hörtnagl, L., Brilli, F., Wohlfahrt, G., and Hansel, A.: Eddy covariance VOC emission and deposition fluxes above grassland using PTR-TOF, Atmos. Chem. Phys., 11, 611-625, doi:10.5194/acp-11-611-2011, 2011. 
Sander, S., Friedl, R. R., Golden, D. M., Kurylo, M. J., Moortgat, G. K., Keller-Rudek, H., Wine, P. H., Ravishankara, A. R., Kolb, C. E., Molina, M. J., Finlayson-Pitts, B. J., Huie, R. E., and Orkin, V. L.: Chemical kinetics and photochemical data for use in atmospheric studies, Evaluation number 15, Vol. JPL Publication 06-2, Jet Propulsion Laboratory, Pasadena, 2006.

Schade, G. W. and Goldstein, A. H.: Fluxes of oxygenated volatile organic compounds from a ponderosa pine plantation, J. Geophys. Res., 106, 3111-3123, doi:10.1029/2000JD900592, 2001.

Schade, G. W. and Goldstein, A. H.: Plant physiological influences on the fluxes of oxygenated volatile organic compounds from ponderosa pine trees, J. Geophys. Res., 107, 4082, doi:10.1029/2001JD000532, 2002.

Schade, G., Solomon, S., Dellwik, E., Pilegaard, K., and LadstatterWeissenmayer, A.: Methanol and other VOC fluxes from a Danish beech forest during late springtime, Biogeochemistry, 106, 337-355, doi:10.1007/s10533-010-9515-5, 2011.

Seco, R., Peñuelas, J., and Filella, I.: Short-chain oxygenated VOCs: Emission and uptake by plants and atmospheric sources, sinks, and concentrations, Atmos. Environ., 41, 2477-2499, doi:10.1016/j.atmosenv.2006.11.029, 2007.

Seewald, M. S. A., Singer, W., Knapp, B. A., Franke-Whittle, I. H., Hansel, A., and Insam, H.: Substrate-induced volatile organic compound emissions from compost-amended soils, Biol. Fertil. Soil., 46, 371-382, doi:10.1007/s00374-010-0445-0, 2010.

Seinfeld, J. H. and Pandis, S. N.: Atmospheric chemistry and physics: from air pollution to climate change, John Wiley \& Sons, Hoboken, NJ, USA, 2006.

Sharkey, T. D., Wiberley, A. E., and Donohue, A. R.: Isoprene emission from plants: why and how, Ann. Botany, 101, 5-18, doi:10.1093/aob/mcm240, 2008.
Singh, H. B., Salas, L. J., Chatfield, R. B., Czech, E., Fried, A., Walega, J., Evans, M. J., Field, B. D., Jacob, D. J., Blake, D. R., Heikes, B. G., Talbot, R., Sachse, G., Crawford, J. H., Avery, M. A., Sandholm, S., and Fuelberg, H.: Analysis of the atmospheric distribution, sources, and sinks of oxygenated volatile organic chemicals based on measurements over the Pacific during TRACE-P, J. Geophys. Res., 109, D15S07, doi:10.1029/2003JD003883, 2004.

Stotzky, G., Schenck, S., and Papavizas, G. C.: Volatile Organic Compounds and Microorganisms, Critic. Rev. Microbiol., 4, 333-382, doi:10.3109/10408417609102303, 1976.

Warneke, C., Karl, T., Judmaier, H., Hansel, A., Jordan, A., Lindinger, W., and Crutzen, P. J.: Acetone, methanol, and other partially oxidized volatile organic emissions from dead plant matter by abiological processes: Significance for atmospheric HOx chemistry, Global Biogeochem. Cy., 13, 9-17, doi:10.1029/98GB02428, 1999.

Warneke, C., Luxembourg, S. L. S., Gouw, J. De, de Gouw, J. A., Rinne, H. J. I., Guenther, A. B., and Fall, R.: Disjunct eddy covariance measurements of oxygenated volatile organic compounds fluxes from an alfalfa field before and after cutting, J Geophys. Res., 107, 4067, doi:10.1029/2001JD000594, 2002.

Wohlfahrt, G., Anfang, C., Bahn, M., Haslwanter, A., Newesely, C., Schmitt, M., Drösler, M., Pfadenhauer, J., and Cernusca, A.: Quantifying nighttime ecosystem respiration of a meadow using eddy covariance, chambers and modelling, Agr. Forest Meteorol., 128, 141-162, doi:10.1016/j.agrformet.2004.11.003, 2005.

Wohlfahrt, G., Hammerle, A., Haslwanter, A., Bahn, M., Tappeiner, U., and Cernusca, A.: Seasonal and inter-annual variability of the net ecosystem $\mathrm{CO}_{2}$ exchange of a temperate mountain grassland: Effects of weather and management, J. Geophys. Res., 113, 101029, doi:10.1029/2007JD009286, 2008.

Zhou, X. and Mopper, K.: Photochemical production of lowmolecular-weight carbonyl compounds in seawater and surface microlayer and their air-sea exchange, Mar. Chem., 56, 201-213, doi:10.1016/S0304-4203(96)00076-X, 1997. 